\title{
Robotics: Breakthrough Technologies, Innovation, Intellectual Property
}

\author{
Andrew Keisner \\ Head, Legal department of drones, Amazon. \\ Address: 410 Terry Ave. North, Seattle, WA 98109-5210. E-mail: candrewkeisner@gmail.com
}

Julio Raffo

Senior Economist, Economics and Statistics Division, WIPO*. E-mail: julio.raffo@wipo.int

\section{Sacha Wunsch-Vincent}

Senior Economist, Economics and Statistics Division, WIPO. E-mail: sacha.wunschvincent@wipo.int

* WIPO - World Intellectual Property Organization, WIPO. Address: 34 chemin des Colombettes, CH-1211 Geneva 20, Switzerland

\begin{abstract}
$\mathrm{R}$

obotics technology and the increasing sophistication of artificial intelligence are breakthrough innovations with significant growth prospects. They have the potential to disrupt existing socio-economic facets of everyday life. Yet few studies have analysed the development of robotics innovation. This paper closes this gap by analysing current developments in innovation in robotics; how it is diffused, and what role is played by intellectual property (IP). The paper argues that robotics clusters are mainly located in the US and Europe, despite a growing presence in South Korea and China. The robotics innovation ecosystem builds on cooperative networks of actors, including individuals, research institutions, and firms. Governments play a significant role in supporting robotics innovation through funding, military demand, and national robotics strategies. Robotics competitions

and prizes provide an important incentive for innovation. Patents are used to exclude third parties to secure freedom of operation, license technologies, and avoid litigation. The countries with the highest number of patent claims are Japan, China, South Korea, and the US. The growing stock of patents owned by universities and PROs, particularly in China, is noteworthy too. Automotive and electronics companies are still the largest patent filers, but medical technologies and the Internet are emerging as new actors in the field. Secrecy is often used as a tool to appropriate innovation. Copyright protection is relevant to robotics also, mainly for its role in protecting software. Finally, open-source robotics platforms are increasingly used in the early stages of the innovation process as they allow new actors in the robotics field to optimize their initial spending on innovation.
\end{abstract}

Keywords: robotics; robot; artificial intelligence; innovation; patent; trade secret; intellectual property; copyright

DOI: 10.17323/1995-459X.2016.2.7.27
Citation: Keisner A., Raffo J., Wunsch-Vincent S. (2016) Robotics: Breakthrough Technologies, Innovation, Intellectual Property. Foresight and STI Governance, vol. 10, no 2, pp. 7-27. DOI: 10.17323/1995-459X.2016.2.7.27 
At bottom, robotics is about us. It is the discipline of emulating our lives, of wondering how we work.

Rod Grupen, Director of the Laboratory for Perceptual Robotics

University of Massachusetts Amherst

$\mathrm{T}$ he rising sophistication of robots and artificial intelligence (AI), and its consequences, are currently the subject of numerous debates. The fact that humanoid robots have recently been trialed in supermarkets, schools, hospitals and retirement homes in Europe, the United States, and Japan has given the field of robotics new prominence in the public eye.

Technologists, economists, lawyers, and experts from other disciplines are speculating about the potential uses of robotics innovation and its socio-economic impacts. In economic circles, the debate often focusses on the potential impact, positive and negative, of employing robots. Social scientists are debating the social influence of artificial companions. Hollywood movies such as Ex_Machina or Her, too, have put the spotlight on the potential upcoming superiority of AI, which could rival human intelligence. Observers agree unanimously that the pervasive uptake and impact of robotics innovation is imminent, and potentially far-reaching.

Yet, despite the attention devoted to this expanding field of technology, few studies have analyzed the developments of robotics innovation and the underlying innovation ecosystem. Moreover, while the role of intellectual property (IP) is analyzed with respect to numerous high-technology fields, such as information-, nano-, or biotechnology, few studies are devoted to the use and uptake of various forms of IP for robotics innovation. The few articles devoted to robotics innovation in prominent innovation journals date back to the 1990s [Kumaresan, Miyazaki, 1999].

This paper aims to fill this gap by providing an up-to-date analysis of the robotics innovation system, and the corresponding role of IP. It first describes the history of robotics innovation, then assesses robotics' underlying economic contribution. Next, the paper describes the robotics innovation ecosystem; and finally analyses the uptake and relevance of different strands of IP to robotics innovation.

The present paper is part of a broader series of studies completed in preparation for WIPO's World IP Report 2015, 'Breakthrough Innovation and Economic Growth' [WIPO, 2015]. That report explores the concrete linkages between innovation, IP, and growth in six areas of breakthrough innovation (airplanes, antibiotics, semiconductors, 3D printing, nano-technology and robotics).

\section{The Development of Robotics}

Robotics is the field of technology that drives the development of robots for application in areas as diverse as car factories, construction sites, schools, hospitals, and private homes. Industrial robot arms have been in use in automotive and other manufacturing businesses for more than three or four decades. However, various strands of existing and newer research fields such as artificial intelligence (AI) and sensing, have been combined in more recent years to produce autonomous and 'advanced' robots for widespread use in the social and economic spheres.

In part driven by aforementioned Hollywood movies, most laypersons perceive 'robots' to be primarily, or exclusively, humanoid robots. However, humanoid robots are only a small subset of the broader robotics industry.

The Encyclopedia Britannica defines a robot as 'any automatically operated machine that replaces human effort.' According to the International Federation of Robotics (IFR), '[a] robot is an actuated mechanism programmable in two or more axes with a degree of autonomy, moving within its environment, to perform intended tasks' [IFR, 2015]. In turn, the majority of practitioners and scholars consider a robot to be any "machine capable of sensing its environment and reacting to that environment based on an independent decision-making capability." [Springer, 2013, pp. 1-5].

The term autonomy is often used to underline the difference between robots and other machines where a robot would have the ability to interpret its environment and adjust its actions to achieve a goal. In terms of technological trajectory, robots are evolving from programmed automation, over semi-autonomous to more autonomous complex systems. Fully autonomous systems are able to operate and make 'decisions' to complete tasks without human interaction.

A remote control device is a device that can be controlled from a remote location. Based on the most common definition of a 'robot', remote controlled devices would not be considered a 'robot'. Nevertheless, the robotics industry has accepted certain purely remote controlled devices as falling within its domain. For example, telepresence devices are often referred to as robots, or even robotic-telepresence devices, despite the fact that some telepresence devices are purely remote controlled. The same is true for certain toys and educational devices. Examples of remote controlled devices frequently considered to be within the bounds of the robotics industry include telepresence robots, remotely controlled humanoid robots, robotic assisted surgical devices, exoskeletons, and Unmanned Aerial Vehicles (UAV), also known as Unmanned Aerial Systems (UAS) or 'drones.'

Semi-autonomous devices still interact with and are controlled by human operators, but are not purely remote controlled devices as they only provide guidance to their human operators to ease and/or assist in the device's operation. Robots whose actions are managed by a human operator is generally considered semi-autonomous. Semi-autonomous features are increasingly becoming more common in cars, as well as certain industrial robots that require an operator to provide detailed commands. 
Fully autonomous devices are able to operate and make 'decisions' within the environment for which it was designed; they are able to further the assigned task without human interaction. Fully autonomous devices are not typically designed to think creatively, but there is some admittedly blurred lines as certain fully autonomous devices are necessarily designed to operate in unpredictable environments for which their decisions are not predetermined.

AI is generally considered to be a niche area of computer science, focused on computer-based devices that are capable of making intelligent human-like decisions. Although admittedly a blurry line, one divide between fully autonomous and $\mathrm{AI}$ is the difference between a device making basic unsophisticated decisions (autonomy) and one that is capable of making creative decisions. AI is considered by some practitioners to be within the robotics industry, but many other practitioners consider artificial intelligence to be its own field of technology with potentially profound implications on the robotics industry. The latter view is based on the understanding that artificial intelligence is grounded in Computer Science without necessarily any hardware application. Although artificial intelligence incorporated into a movable hardware device is an anticipated reality within the robotics industry, it can stand entirely separate from any hardware device.

\section{History of Robotics}

\section{Industrial arms for automation}

Robots, in their most basic form, are not new. The history of robotics started in ancient Greek with automatons, essentially non-electronic moving machines that displayed moving objects. The invention of simple automatons continually evolved thereafter, but robots in their current form took off with the process of industrialization, essentially to perform repetitive tasks.

More recently, a few key inventions in two areas stand out as having led to the first incarnation of robots for industrial automation [IFR, 2012]. First, control systems allowing humans or computers to control and steer robots from a distance, and second, mechanical manipulation systems such as robotic arms or legs to move or grab objects.

As for mechanical manipulation systems, the first industrial robot was developed in 1937 in the form of a small crane. In 1942, William Pollard and Harold Roselund, both employees of DeVilbiss Company, filed a patent for the first programmable mechanized paint-sprayer. The development of robotic legs and arms was furthered by William Walter, who built the first autonomous robot in the late 1940s [US Patent $2,679,940]$. However, the real breakthrough that propelled the development of the robotics industry is attributed to George Devol, who invented and patented the first automatically operated programmable robotic arm in the mid-1950s [Nof, 1999]. Devol then partnered with Joseph Engelberger, considered by many scholars to be the 'Father of Robotics,' ${ }^{1}$ to create a company called Unimation. This marked the beginning of the commercialization of industrial robots [Rosheim, 1994]

Robotic arms have since been fine-tuned and improved. The first computer-controlled revolute electric arm, for instance, was developed at the Case Institute of Technology, Case Western Reserve University, US. In 1969, researchers at Stanford University invented the so-called Programmable Universal Manipulation Arm that enabled a more sophisticated control for assembly and automation [Scheinman, 2015]. One of these researchers, Victor Scheinman, started Vicarm Inc., which proved fundamental to the development of the robotics industry; he ultimately sold the company to Unimation in 1977.

Largely based on the work of the aforementioned inventors and firms, the first commercial robots were deployed in General Motors' assembly lines in the USA in 1961 [IFR, 2012]. The first industrial robot in Europe, a Unimate, was installed in Sweden in 1967. In 1969, the company Trallfa of Norway offered the first commercial painting robot. In 1973, ABB Robotics and KUKA Robotics introduced the first robots in the market. Since then the robotics industry has been continually working to improve the functionality and control of robotic mechanical parts.

Approximately a decade after Devol filed his patent, Japanese companies began to develop and produce their own robots pursuant to a license agreement with Unimation. By 1970, robotic manufacturing had proliferated throughout the automotive industry in the US and Japan. By the late 1980s, Japan - led by the robotics divisions of Fanuc, Matsushita Electric Industrial Company, Mitsubishi Group, and Honda Motor Company - had become the world leader in the manufacture and use of industrial robots.

Parallel key inventions in the area of packaging robots - for instance, the Delta packaging robot developed at the Federal Institute of Technology of Lausanne that yielded 28 patents - modernized the packaging industry.

A full-scale humanoid robot developed at Waseda University in Japan laid the foundation for follow-on innovation in the field. It facilitated enhanced human-robot interaction relevant to today's consumeroriented robot markets. While many historians have discussed evidence of early pre-computer based use of 'legs' for movement, the initial breakthroughs concerning machines that could walk on two or more legs occurred in the 1960s and 1970s. Yet, such technology is not yet prevalent within commercialized products despite decades of research in the field.

\footnotetext{
${ }^{1}$ It should be noted, however, that many scholars and practitioners, especially those that consider remote controlled devices to be part of the robotics field, also consider Nikola Tesla to be the 'Father of Robotics' based, at least in part, on his 1898 invention and patent of a remote controlled boat (see United States Patent No. 613,809).
} 


\section{Autonomous systems built on artificial intelligence and connectivity}

In the journey towards more capable robots, researchers have worked on increasing autonomy and improving interaction between humans and robots. New materials and innovations in various fields outside the robotics area such as artificial intelligence (AI), mechatronics, navigation, sensing, object recognition, and information processing are the core technological developments furthering robotics today [Kumaresan, Miyazaki, 1999].

In particular, innovation in software and AI will be key technologies for next-generation robots that can effectively manoeuvre and circumvent obstacles. The seminal breakthrough in developing algorithms instrumental for robotic path planning took place in the mid-1980s and is credited to Randall Smith and Peter Cheeseman [Smith and Cheeseman, 1986]. The result of such seminal research on the problem of Simultaneous Localization and Mapping (SLAM) led to the development of SLAM algorithms. Many robotics companies still use SLAM algorithms to this date, albeit with modifications tailored to the environment and purpose of their specific robot. Algorithms have become central to the development of robots that can make increasingly complex decisions; for instance, for simulating emotions in home or service robots. Researchers are currently working on software that will mimic the human brain, honing language and decision-making skills.

Due to improved connectivity, sensors, and processing power, robots are becoming increasingly datadriven, and linked over more intelligent networks. As such, innovation is increasingly about software and hardware integration and the development of so-called integrated robotic and intelligent operational systems. On the application level, the development of autonomous vehicles and drones is seen as an extension of robotics.

\section{The Economic Contribution of Robotics}

The industrial robot market has been estimated to be worth USD $\$ 29$ billion in 2014, including the cost of software, peripherals, and systems engineering (Table 1). The number of robots sold reached about 230,000 units sold in 2014, up from about 70,000 units in 1995 (Figure 1a). This is projected to increase rapidly in the next few years.

Interestingly, the respective shares of various world regions in global robotics sales have changed little. Asia leads in this area, followed by Europe and North America, while sales in South America and Africa are rather small in volume. Within Asia, China has gone from no robots in 1995 to becoming the largest market for robots, overtaking Japan. South Korea is now the second biggest user of industrial robots in Asia. $^{2}$

\section{Figure 1. Key indicators of global trade in industrial robots}

a) Shipments in thousands of units, 1995-2014

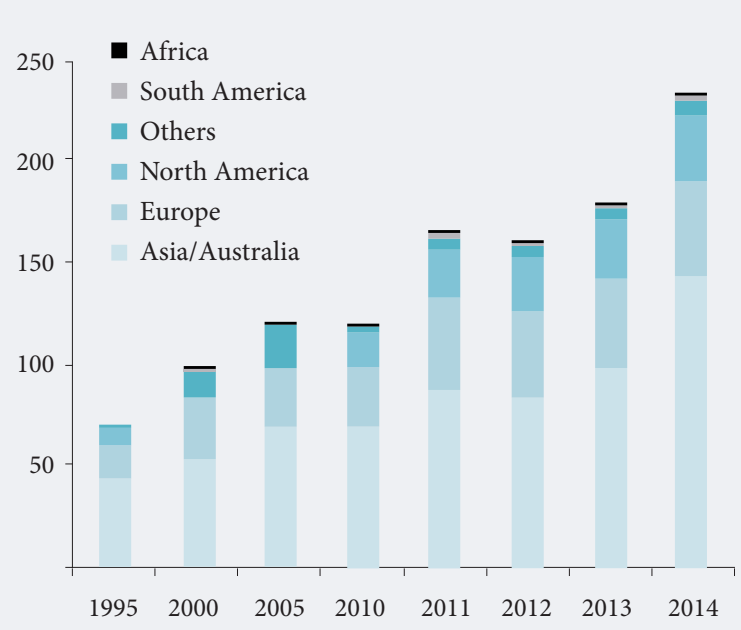

b) Share of sectors as percent of total shipments, 2014

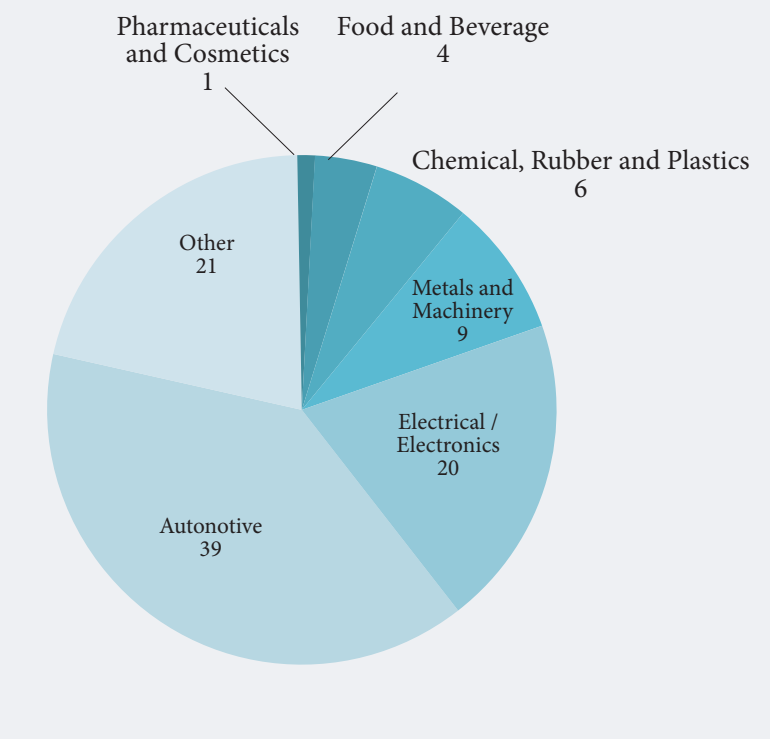

\footnotetext{
${ }^{2}$ In terms of robotic density, as of 2014 the Republic of Korea had the highest robot density in the world, with 437 units per 10,000 persons employed in the manufacturing industry, followed by Japan (323) and Germany (282). In comparison, China's density was 30, Brazil's 9, and India's 2 [IFR, 2014a].
} 
Table 1. Different estimates of the robotics industry revenues

\begin{tabular}{|l|l|l|}
\hline \multicolumn{1}{|c|}{ Определение } & \multicolumn{1}{|c|}{ Оценка } & \multicolumn{1}{|c|}{ Источник } \\
\hline Global market for industrial robotics & $\begin{array}{l}\text { USD 29 billion (2014) } \\
\text { USD 33 billion (2017) }\end{array}$ & [IFR, 2014a] \\
\hline Global market for industrial robotics & EUR 50-62 billion (2020) & [euRobotics, 2014] \\
\hline Global market for service robots & $\begin{array}{l}\text { USD 3.6 billion (of which USD 1.7 billion } \\
\text { for domestic use) }\end{array}$ & [IFR, 2014b] \\
\hline
\end{tabular}

In terms of sectors, the automotive industry continues to be the main driver of automation, followed by electronics (Figure 1b). Innovation will enable more flexible and small-scale manufacturing.

A novel robotics field is the production and use of service robots in areas outside of manufacturing. This category includes robots intended for 'professional use' in agriculture, mining, transport (including the large field of unmanned aerial and land vehicles), health, education, space and sea exploration, unmanned surveillance, and other fields [IFR, 2014b].

The total number of professional service robots reached USD 3.6 billion in 2014, projected to lead the growth of upcoming robotic use [IFR, 2014b]. The largest markets are Japan, South Korea, the US, and Europe and the sectors leading their use are defence, logistics, and health. Surgical robot device markets, valued at USD 3.2 billion in 2014, are anticipated to reach USD 20 billion by 2021 [Wintergreen Research Inc., 2015].

In addition, robotics in personal and domestic applications - another novel field - has experienced strong global growth with relatively few mass-market products. These include floor-cleaning robots, mowers, robots for education, and assistive robots for the elderly [IFR, 2014b].

A few consultancy reports have emphasized the wide range of savings generated through advanced robotics in healthcare, manufacturing, and services. These reports predict high benefits to economic growth. The McKinsey Global Institute estimates that the application of advanced robotics could generate a potential economic boost of USD 1.7 trillion to USD 4.5 trillion a year by 2025, including more than USD 2.6 trillion in value from healthcare uses [McKinsey Global Institute, 2013]. However, quantifying the productivity-enhancing contribution of robots in definite terms is challenging.

Robots can increase labour productivity, reduce production costs, and improve product quality. In the service sector in particular, robots can also enable entirely new business models. In part, the economic gains of robots are directly linked to substituting - and thus automating - part of the currently employed workforce [Metra Martech, 2011; Miller, Atkinson, 2013; Frey, Osborne, 2013; Brynjolfsson, McAfee, 2014]. On the one hand, productive labour helps keep manufacturing firms competitive, avoiding their relocation abroad, and creating higher-wage jobs. The robotics industry has been particularly focused over the past several years on alleviating fears that it will cause a decrease in available jobs. Indeed, the industry has conducted research and found evidence to support projections that increased employment opportunities will follow from the advancement and proliferation of robotics [Metra Martech, 2011]. This above all concerns certain high-income nations as a result of manufacturing re-shoring (also called manufacturing in-shoring); in other words, manufacturing previously outsourced to nations with cheaper labour will be relocated to high income nations as robotics would reduce the cost of manufacturing [Green, 2012; Christensen et al., 2013]. If such predictions are accurate, it may be true that the proliferation of robotics will increase jobs and economic growth in high income countries. However, in the manufacturing sector if the primary concern remains low labour costs, the creation of jobs in high income countries may be at the expense of jobs in middle and low income countries. ${ }^{3}$

On the other hand, the use of robots is certain to eliminate both low-skilled but also some types of higherskilled jobs hitherto unaffected by automation. Yet, there are still multiple sources that predict robotics, as a whole, will lead to an increase in available jobs. Many of these later reports focus only on the loss of current jobs [Frey, Osborne, 2013] and do not account for the creation of new job types that may not exist today. On balance, the employment effect of robotics is currently uncertain.

A little researched issue is the extent to which robotic innovations have diffused to low- and middleincome countries, and the effects of this diffusion. Nevertheless, it is expected that firms involved in manufacturing and assembly activities for global or local supply chains, will need to upgrade their use of robots, including those in middle-income or even low-income economies where they have so far competed on cheap labour alone.

Although the location of companies developing robots and robotics products appears to be occurring in specific high income nations, the impact of certain robotics technologies may have an impact, akin to that of the Internet, in middle and low income countries. In the same way that the Internet has allowed certain jobs to be performed remotely, whether from a location in the same region or a different continent, robotics technologies such as telepresence robots or remotely controlled robots with arms will augment the type of jobs that can be performed from a remote location. As the Internet continues to evolve, it will inspire a natural progression from sensing at a distance to taking action at a distance. This extension of

\footnotetext{
${ }^{3}$ From 2013 in China, we see low demand for robotics. Experts predict that China's demand for robotics will increase due to the need for China's manufacturing industry's to stay competitive [RBR Staff, 2012].
} 


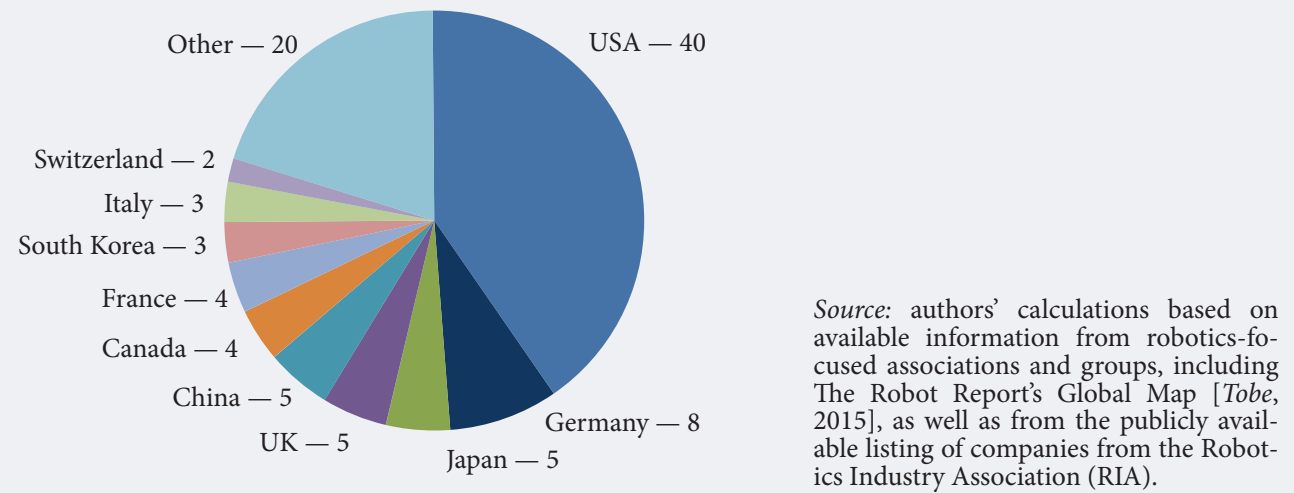

the Internet into the physical world will serve to further blur the boundaries among community, communication, computing, and services and inspire new dimensions in telecommuting and telepresence applications. Hybrid solutions are likely to emerge that enable distributed human cognition and enable the efficient use of human intelligence. Such solutions will combine the robotics-enabled capability to remotely and autonomously perceive situations requiring intervention with the Internet-enabled capability for human operators to take action from a distance on an as-needed only basis [Christiansen, et al., 2013, p. 66]. As the Internet and robotics technology continue to evolve and make the location of an employee secondary to the ability to perform certain tasks, any nation with sufficiently fast and reliable internet service could enable its citizens to compete for jobs. In particular, middle and low income countries may be able to compete for jobs requiring a higher level of intellect or creativity in higher income countries. This phenomenon already exists as a result of the Internet, with certain companies thriving because of their wide geographical reach for skilled labour [Halzack, 2014]. Such tasks are primarily restricted to purely Internet-based deliverables but with the advancement of certain robotics technologies, they could involve physical jobs as well. Although middle and low-income nations may not benefit from such advancements if they have slow, unreliable, or heavily restricted Internet, technologies are being developed to resolve such limitations [Garside, 2014; Dockterman, 2014; McNeal, 2014].

\section{The Robotics Innovation System}

With the evolution from the era of industrial automation to the use of advanced robotics across the economy, the robotics innovation system also changed. In its present day form, this system can be characterized by a few key traits.

\section{Robotics clusters with strong linkages between actors}

Robotics innovation predominantly occurs within a few countries and clusters [Green, 2013]. These clusters thrive on the interface between public and private research, with firms commercializing the resulting innovation.

Robotics clusters are mainly located in the US, Europe (in particular, Germany and France, and to a lesser extent the UK), and Japan. They are increasingly found in South Korea and China (Figure 2). ${ }^{4}$ Applicants from these countries account for the vast majority of patent applications in the field of robotics (Figure 3). Relative to GDP, Canada, Denmark, Finland, Italy, Israel, the Netherlands, Norway, the Russian Federation, Spain, the UK, Sweden, and Switzerland stand out as economies with the largest presence of innovative robotics firms.

In the early stages of robotics, the key players were inventors from the US, Europe, and slightly later, Japan. In the early 2000s, key actors also started to come from South Korea and then China [UKIPO, 2014]. Within these few countries, robotics clusters are concentrated around specific regions, cities, or top universities in the field. For example, Boston, Silicon Valley, and Pittsburgh in the US are generally regarded as the three main robotics clusters. In Europe, the Île-de France region (particularly for civilian drones), Munich in Germany, Odense in Denmark, Zürich in Switzerland, and Robotdalen in Sweden are prominent. In Asia, Bucheon in Korea, Osaka and Nagoya in Japan, and Shanghai and Liaoning Province in China are key robotics clusters.

Some companies that excel in robotics innovation are located outside these clusters. They are usually well established in the automotive sector. Increasingly, reputed Internet companies are also entering the field

\footnotetext{
${ }^{4}$ Although there is no standard global database for all robotics companies, there have been some attempts to compile such lists [Tobe, 2015].
} 


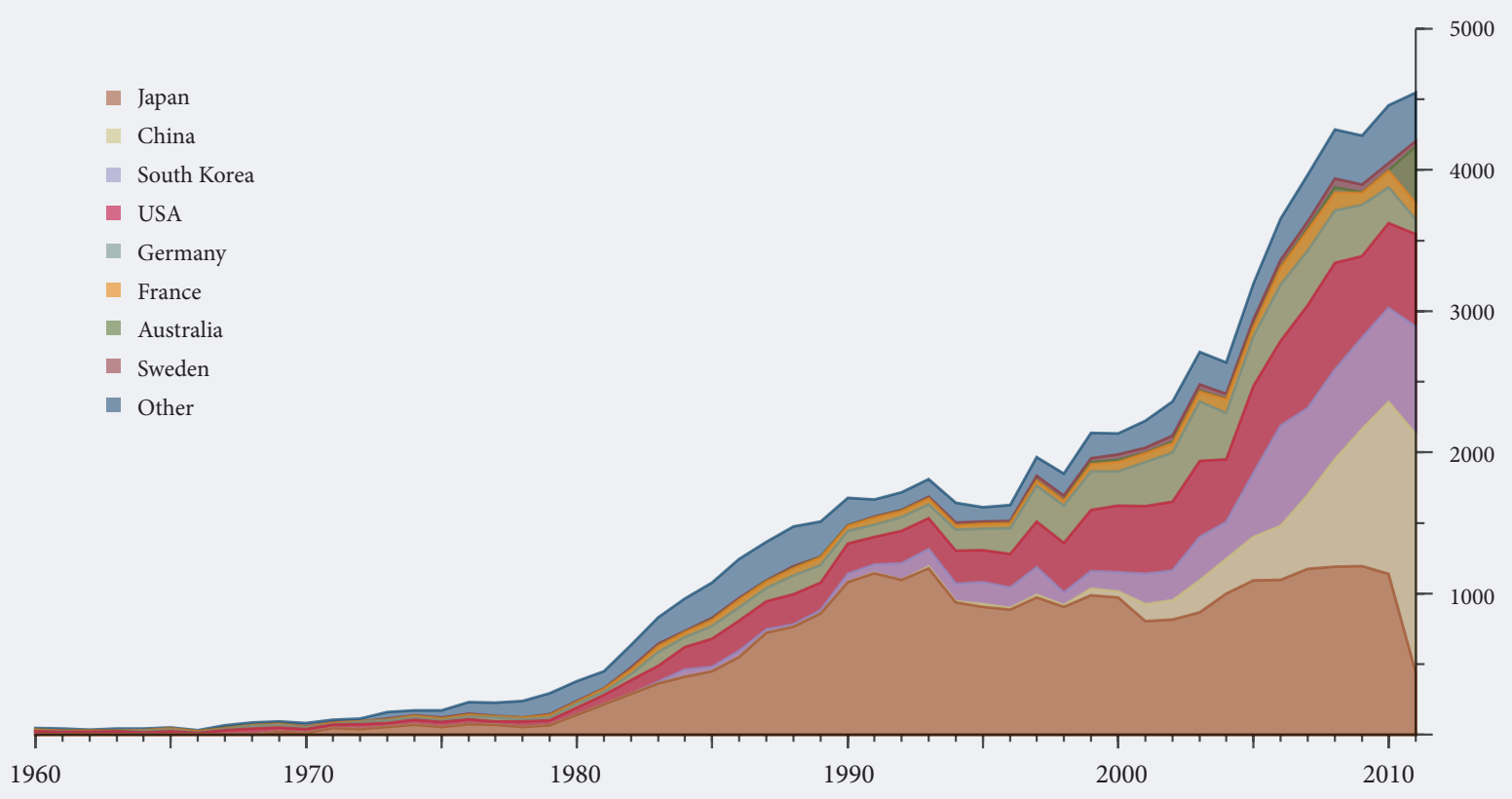

Note: Only the first filings with at least one patent granted within the patent family are counted.

Source: WIPO based on the PATSTAT database.

of robotics since they have the solid experience, financial means, and the skills to hire robotics experts. China has seen a strong surge in robotics patents and it also hosts some of the fastest-growing robotics companies such as DJI (Drone Company), as well as new industrial robot manufacturers such as Siasun and Estun that have driven down the cost of industrial robots.

\section{Highly dynamic and research-intensive collaborative robotics innovation ecosystem}

The robotics innovation ecosystem comprises a tight and cooperative network of actors, including individuals, research institutions, and universities, as well as large and small technology-intensive firms. Robotics brings together diverse science and technology breakthroughs to create new applications.

Select public research institutions are also crucial actors in the robotics innovation ecosystem. Public Research Organizations (PROs) of note include the Korean Institute of Science and Technology, the Fraunhofer institutes in Germany, the Industrial Technology Research Institute in Taiwan (Province of China), and the Russian Academy of Sciences. Examples of leading universities include McGill (Canada), Carnegie Mellon (the US), ETH (Switzerland), Imperial College (UK), Sydney University (Australia), Osaka University (Japan), and the Shanghai Jiao Tong University (China).

Traditionally, these science institutions play an important role in innovation by conducting long-term research whose commercial applications will only be realized far in the future [Nof, 1999, p. 33] As depicted in Figure 4, the role of academic and public institutions, as well as that of individual entrepreneurs, varies through time and across countries. In addition, academic institutions continue to play a major role in furthering development in robotics through creating spin-outs and spin-offs, patents and through close collaboration with firms [Nof, 1999]. Collaboration between firms and PROs is tight too; for instance, the firm KUKA is developing lightweight robots with the German Institute of Robotics and Mechatronics. Furthermore, the increased number of formal robotics degrees offered by academic institutions has been critical in the development and diffusion of skills, as corporations tend to hire recent graduates.

There are also examples of universities collaborating with the private sector beyond monetary support for robotics research, including joint development agreements to build robotic technology aided solutions for private companies. ${ }^{5}$

\footnotetext{
5 [RBR Staff, 2013b] discusses Carnegie Mellon University's five-year joint development agreement with Anglo American Plc, pursuant to which CMU's Robotics Institute will design, build and deploy mining robots, robotics tools and autonomous technologies in partnership with Anglo American's internal Technology Development Group. See also Deere \& Company's joint development with University of Illinois as evidenced in jointly assigned United States Patent Nos. 7,587,081; 8,712,144; 8,737,720; and 8,855,405; and Deere \& Company's joint development with Kansas State University (as evidenced in the jointly assigned United States Patent Nos. 7,792,622; 7,684,916; 7,580,549; and 7,570,783); and MAKO Surgical Corp.s joint development with the University of Florida (as evidenced in jointly assigned United States Patent Nos. D625,415 and D622,854).
} 


\section{Figure 4. Geographic distribution of robotics innovations by country of origin: 1960-2011}
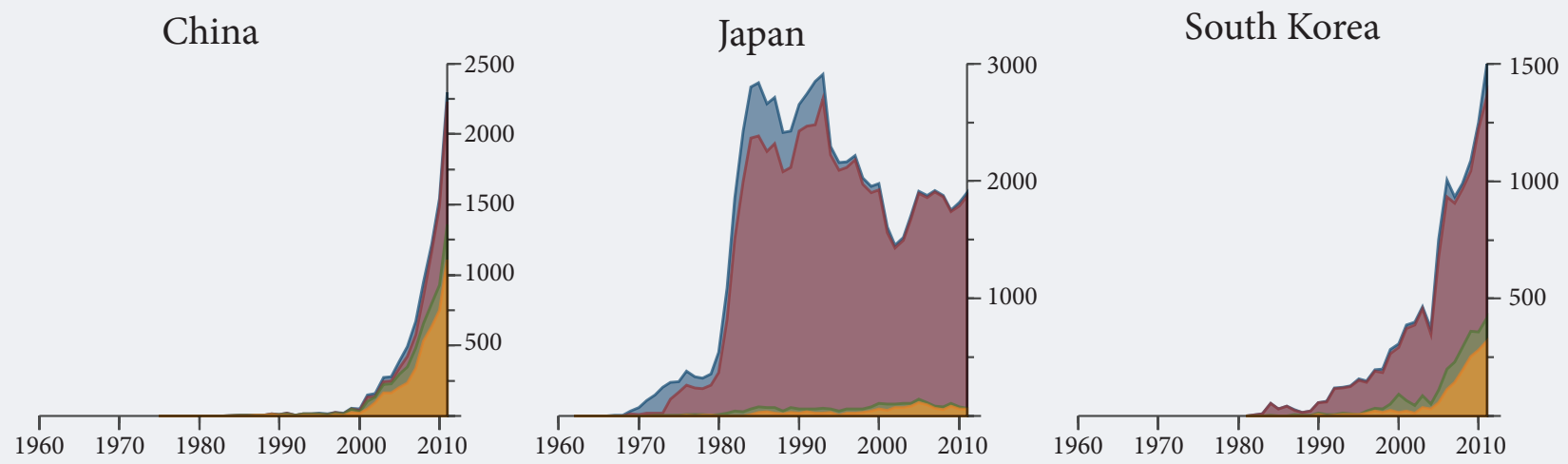

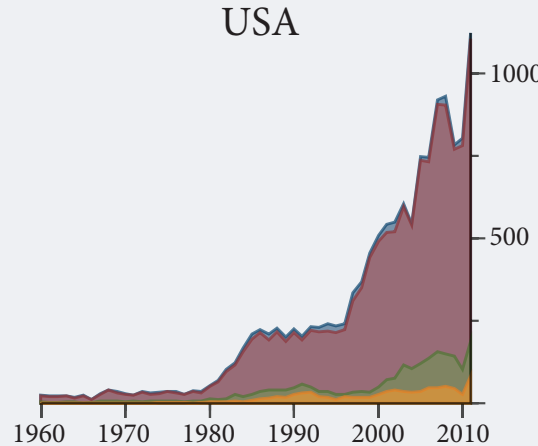

- Academia and public sector

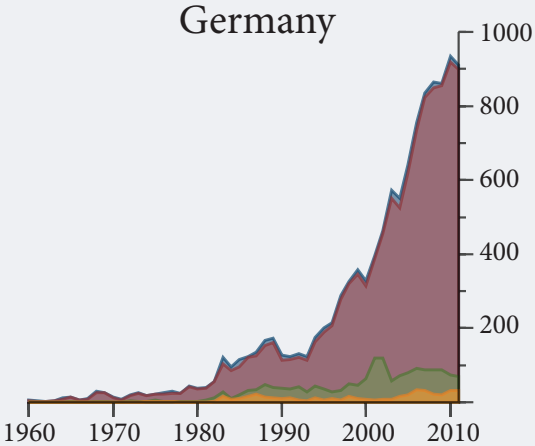

- Companies

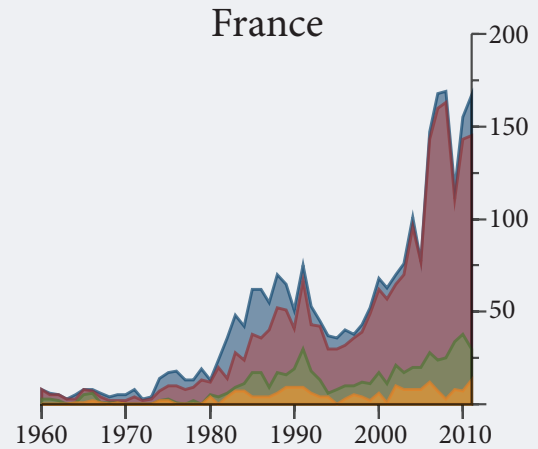

- Not available

Source: WIPO based on the PATSTAT database.

Universities may be more willing to focus on research and development that may not have immediate commercialization potential. However, they still strive to protect their inventions, which in future may lead to new robotics products or companies. Indeed, research institutions conducting research in the field of robotics frequently patent inventions. Additionally, there are numerous companies within the industry that are 'spinoffs' or 'spinouts' of research and development projects conducted at universities [Cellan-Jones, 2014]. ${ }^{6}$

Three main types of innovative robotics firms can be identified:

1. Small company startups or specialized robotics firms that are often created by individual inventors affiliated with academic robotics centers or clusters, sometimes with significant direct or indirect government support. An example is Universal Robots, which emerged from a robotics cluster in Demark with links to the Danish Technological Institute, receiving initial government and seed funding.

Although parts of the industry are more mature today, the potential for small robotics startups is still large. In the early stage of radical innovation, small startups demonstrate more agility and speed, and closer interaction with academia. In addition, innovation ecosystems are becoming more specialized, allowing for niche specialist companies. Third-party external developers are increasingly part of the robotics innovation system because robotics platforms, often based on open source software architectures, are the starting point for further development. Further, a growing number of companies provide roboticsrelated services such as mobility or machine management systems. The rise of new, more consumeroriented robotics firms and new funding mechanisms enable start-ups to appear. For instance, Play-I (now called Wonder Workshop) focuses on creating educational toy robots and recently raised money through crowd-funding platforms.

\footnotetext{
${ }^{6}$ Startup companies in the robotics field that are spinoffs/spinouts of research conducted in a university setting are common in the US but also occur quite often in Europe and Asia. Examples include Oxbotica (a spinout of Oxford University), Empire Robotics (a spinoff of Cornell University), Autonomous Solutions, Inc. (a spinoff of Utah State University), and Blue Belt Technologies, Inc., RE2, Inc., and Medrobotics Corp. (all spinoffs of Carnegie Mellon University). Medrobotics Corp. recently raised USD 20 million in a Series F funding round. In late 2013, Google acquired Meka Robotics (a spinoff of Massachusetts Institute of Technology) and Schaft Inc. (a spinoff of University of Tokyo).
} 
2. Large, established robotics companies such as ABB (Switzerland), Kawasaki Heavy Industries, Yaskawa and Fanuc (Japan) and KUKA (Germany) that are active in robotics R\&D, and initially focused on industrial robot research and production alone. Scale matters, as innovating in the field of industrial robotics hardware is particularly capital-intensive and research takes years to materialize. Major clients in the automotive sector, for instance, are only willing to buy from large, trusted, established companies to avoid safety risks. In addition, large robotics firms are emerging thanks to the growing demand for service and household robots. Although still making most of its revenue from the development and sale of robots for military applications, iRobot (US) is one such example. Initially a spin-off from MIT, it is now a large company producing robots for security purposes, businesses, as well as private households.

3. Large firms outside the robotics industry have also gained related competencies. Firms such as BAE Systems (UK) in the area of defence, aerospace, and security continue to be important players for robotics innovation. In addition, firms in the automotive sector continue to be significant, not least due to their extensive use of robots. A newer development is the increasing involvement of electronics and ICT firms such as Samsung (South Korea) and Dyson (UK). As robotics becomes more reliant on connectivity and ICT networks, Internet or IT-related firms such as Amazon, Google and Facebook (of the US) as well as Indian ICT services firm such as Infosys, Alibaba of China and Foxconn of Taiwan are joining the fray. They often acquire shares in, or take full ownership of, established robotics firms. Moreover, firms in the health sector are increasingly prominent in robotics research. Market leaders in the area of surgical robots include Intuitive Surgical, Stryker, and Hansen Medical.

As the advantages of robotics have become increasingly visible to non-robotics companies, traditional companies have stepped up their focus on obtaining robotics capabilities to provide business solutions. Such a desire to embrace robotics technology has materialized into significant strategic business decisions that include acquisitions of robotics companies whose technology could directly benefit the acquiring company's business and/or could replace the acquiring company's business. ${ }^{7}$ Traditional companies also enter into joint development agreements with robotics companies for the purpose of developing robotics solutions aimed at the traditional companies' business. ${ }^{8}$ Alternatively, these traditional companies create their own internal robotics divisions by hiring individuals with robotics experience, ${ }^{9}$ and by forming strategic alliances to create a new robotics ecosystem or 'cluster'.

Recently private companies are attempting to tackle particularly difficult problems in the robotics industry by using monetary incentives through crowdsourcing competition programmes. For example, in September 2014, Amazon Inc. announced the 'Amazon Picking Challenge', in which corporate and university teams had to solve the complicated problem of warehouse picking [Romano, 2014; Gamell, 2014]. This type of 'challenge' is similar to the open entry competitions like the United States' Defense Advanced Research Projects Agency (DARPA) Robotics Challenge or the prior DARPA Grand Challenge. Publicly available information concerning formal partnerships and joint development agreements, as well as analyses of patent filings covering robotics technology suggest a significant degree of collaboration for development of robotics technology [UKIPO, 2014, pp. 13-16]. There are several reasons for the greater amount of collaboration in the robotics industry compared to other industries:

1. When it comes to government contracts, and particularly defence contracts with the United States government, the project is sometimes divided among more than one robotics company. The government will frequently award the design and fabrication of the mechanical and electrical aspects to one company, and hand over the software design and building to a different company [Robotics Trends Staff, 2007].

2. The problems that robotics companies tackle are often extremely complex involving multiple disciplines. Most small and medium robotics companies do not have experts from all the engineering disciplines necessary to build a sophisticated robot. The complexity of the technological challenges in building such products explains why even large robotics companies enter into joint development agreements with each other. $^{10}$

3. Customized autonomous systems are now common in medical device manufacturing companies, pharmaceutical companies, and laboratories. Some companies and labs have an internal robotics and automation group that work on certain projects independently, as well as collaborate with specialized robotics companies whenever presented with a particularly time consuming or otherwise challenging assignment. ${ }^{11}$

\footnotetext{
${ }^{7}$ Notable examples of traditional companies acquiring robotics companies include (i) Amazon.com Inc.'s acquisition of Kiva Systems, Inc.; (ii) Stryker Corp.'s acquisition of MAKO Surgical Corp.; and (iii) Advantech Co.'s acquisition of LNC Technology [Letzing, 2012; Walker and Stynes, 2013; Chen, 2013].

${ }^{8}$ Notable examples of traditional companies entering into joint development agreements with robotics companies for the purpose of developing robotics technology directly applicable to the traditional company's business include (i) Anglo American's partnership with Autonomous Solutions, Inc.; (ii) Lowe's Companies, Inc's partnership with Fellow Robots; and (iii) John Deere's joint development with iRobot Corporation. These joint development agreements materialized in jointly assigned patents (United States Patent Nos. 8,874,300; 7,894,951; 8,020,657; and 8,473,140).

${ }^{9}$ In 2014, Amazon.com Inc. advertised for jobs for individuals with experience and skills relevant to its then recently formed drone division [Anders, 2014].

${ }^{10}$ A notable example of joint development agreements between robotics companies includes iRobot Corporation's joint development and licensing agreement with InTouch Technologies Inc. [InTouch Health, 2011]. This agreement was reinforced by the jointly assigned United States Patent No. 8,718,837.

${ }^{11}$ Although internal robotics and automation divisions within traditional companies are not necessarily publicly promoted, a search of robotics-focused patents assigned to traditional companies outside the technology industry demonstrate that robotics related innovation is at least occurring within traditional companies in areas relevant to those companies' business. For example robotics and automation related patents assigned to Pfizer Inc. (United States Patent Nos. 5,370,754; 6,489,094); Abbott Laboratories (United States Patent Nos. 6,588,625; 8,318,499); and Deere \& Company (United States Patent Nos. 7,861,794; 8,195,342; $8,295,979 ;$ and $8,874,261)$.
} 
The high degree of collaboration surrounding the development of robotics technology suggests that joint development projects as well as personal contacts, are both meaningful mechanisms and avenues through which knowledge and skills relevant to robotics technology are diffused. Although the degree to which such knowledge and skills are diffused through scientific publications and the publication of patent applications remains unknown, this study is confident that both these publication mechanisms are used within robotics for acquiring knowledge of technological developments within the industry. Informal interviews with IP directors in numerous prominent robotics companies confirmed that several robotics companies regularly monitor the patent applications published by their competitors. This is done to:

- learn about new technological developments in the sector relevant to their business;

- obtain insights into a competitor's plans to either improve an existing product or create a new one, and find out whether a competitor is attempting to obtain patent protection for something that should be challenged as either non-novel or obvious.

However, it is not merely competing robotics companies who monitor the publication of patent applications. When patent applications are published concerning an invention of particular interest, especially when it relates to a potentially transformative technology for a publicly well-known company, it is common for the patent application to become the subject of an article. ${ }^{12}$

Generally, the exchange of knowledge within the robotics ecosystem currently seems extensive and fluid. This is benefited by the science-intensive nature of robotics innovation and the strong role of science and research institutions, but also by the admittedly nascent phase of many advanced robotics developments. Scientific papers and conferences - such as the International Symposium on Industrial Robots - play a key role in the transfer of knowledge. Moreover, robotics contests and prizes rewarding solutions to specific challenges enable researchers to learn and benchmark their progress, and to close the gap between robotics supply and demand.

Finally, decentralized software-enabled innovation is likely to increase in the future as robots become more widespread, and robot platforms and systems more standardized. In practice, a wider set of external firms and partners will be able to deliver customized solutions to existing proprietary robotic software platforms. This will enable greater modularity in innovation.

\section{Government support for orchestrating and funding innovation}

Governments and their institutions have played a major role in supporting robotics innovation. In particular, governments have funded technological advancements in the defence sector, which are kept confidential for some time. Later, these advancements are ultimately disclosed for non-military and commercial purposes, which contributes to progress in the robotics industry [Springer, 2013, pp. 15-16]. Beyond important research funding and standard innovation support measures, a few specific policy mechanisms deserve to be mentioned:

- Creation of special research institutions or research networks: Examples include the Swiss National Centre of Competence in Research Robotics, which federated research labs, and the Korea Robot Industry Promotion Institute, set up to promote technology transfer.

- R\&D grants and public procurement: Governments, and often the military, fund robotics innovation and create demand via grants or pre-commercial procurement. In the US, R\&D contracts mainly with the National Institutes of Health and DARPA are the primary catalysts [Mireles, 2006; Springer, 2013; Siegwart, 2015]. Pre-commercial procurement of robotics solutions for the healthcare sector, for instance, is part of the EU Horizon 2020 grants. Governments have also incentivized innovation and advancement within the robotics industry through various types of incentive programmes. In the United States, for example, the government incentivized private companies and universities to create autonomous vehicles by offering a substantial monetary sum to whomever accomplishes a set task [Mireles, 2006]. Other governments have provided tax breaks for robotics companies, though some argue that such incentives primarily incentivize the relocation of robotics companies rather than innovation. On the other hand, some countries provide grants for prototype-stage products to be used within an industry with potential customers. This alleviates the particularly lengthy time gap between the creation of a functional prototype and a commercialized product that has been more rigorously tested and satisfies arduous regulatory requirements [Technopolis, University of Manchester, 2011].

- Organizer of contests, challenges, and prizes: Japan organizes Robot Olympics; the UK recently held a competition for driverless vehicles; and the DARPA Robotics Challenge is a landmark.

- Incentives for collaboration, technology transfer, and incubation: Through grants or contracts, governments frequently encourage collaboration and technology transfer. The EU Horizon 2020 Robotics project, for instance, stimulates public-private collaborative projects of a multi-disciplinary nature. In addition, government activities aim to facilitate cluster development, entrepreneurship, and industry networking. In France, for example, the government created the seed fund 'Robolution Capital.'

- Regulations and standards: Legal scholars disagree about the extent to which regulations actually spur or inhibit the growth of technological advancement in the robotics industry. Nevertheless'

\footnotetext{
${ }^{12}$ See for example [Falconer, 2014], who analyses Sony Corporation's potential strategy to develop personal robots based on the publication of United States Patent Application No. 2014/0074292, filed on April 16, 2012, entitled 'Robot device, method of controlling robotic device, computer program, and program storage medium'.
} 
there seems to be a general consensus that half-fledged, categorical regulations have the potential to restrict such advancements [RoboLaw, 2014, p. 10; Pilkington, 2014]. One of the primary areas in need of attention is the reform of current safety standards applicable to robotics, particularly those requiring a clear separation of workspace between humans and robots. Safety is a multidimensional issue extending beyond technology to include numerous governmental and industry standards as well as independent certification and liability exposure. Clear standards are needed for both professional and personal robotics to provide all stakeholders with the transparency necessary for rapid innovation and adoption [Christensen et al., 2013, p. 84]. Furthermore, governments can also hinder innovation in the private sector via burdensome regulations [The Economist, 2014; RoboLaw, 2014, p. 10] Yet, aside from the restrictive regulations applicable to drones and Unmanned Aerial Vehicles (UAVs) in several nations, no regulations exist specifically for most other robotics related technologies. ${ }^{13}$

In addition to the above, many of the more developed countries, including China, have announced special robotics action plans in recent years. These strategies generally include specific monetary investments for robotics research and innovation, measures to improve robotics education, and technology transfer (Table 2).

\section{Robotics Innovation and Intellectual Property}

The focus of robotics innovation is shifting from industrial automation to more advanced robotics involving various technological fields, actors, and economic sectors. As a result, related IP and other strategies to appropriate returns on innovation investment are embryonic and our understanding of what they should look like is incomplete. In addition, recognizing the broad scope of the robotics industry is important because the large variety of robotics products and their applications means that there is no 'one-size-fits-all' IP strategy for robotics companies. Furthermore, observations and trends related to one segment are not necessarily relevant to other segments of the robotics industry.

Some tentative findings on appropriation strategies do, however, emerge based on existing literature, data, and insights from industry practitioners and robotics researchers.

\section{Methodology of patent analysis}

Part of the empirical analysis of this paper relies on a tailor made patent mapping. The patent data for these mappings come from the WIPO Statistics Database and the EPO Worldwide Patent Statistical Database (PATSTAT, April 2015).

The patent mapping strategy was adapted from the seminal work by the UKIPO [UKIPO, 2014]. This work combines the Cooperative Patent Classification (CPC) and International Patent Classification (IPC) symbols with text terms searched for in titles and abstracts. In particular, we have included the following list of IPC and CPC symbols: B25J 9/16, B25J 9/20, B25J 9/0003, B25J 11/0005, B25J 11/0015, B60W 30, B60W2030, Y10S 901, G05D 1/0088, G05D 1/02, G05D 1/03, G05D2201/0207, and G05D 2201/0212; we complemented these with the following terms: robot, robotics, and robotic.

The resulting sample was benchmarked against a list of seminal patents and a list of robotics companies. The latter was compiled - along with their geographic locations and the company type - based on information about robotics companies available to robotics-focused associations and groups, including The Robot Report's Global Map, as well as from the publicly available listing of companies from the Robotics Industry Association (RIA). These sources are useful to corroborate the location of robotics companies and the formation of robotics clusters. However, identifying robotics companies by such

\section{Table 2. National robotics initiatives}

\begin{tabular}{|l|l|}
\hline \multicolumn{1}{|c|}{ Initiative } & Jurisdiction (Year of initiative) \\
\hline National Robotics Initiative Advanced Manufacturing Partnership & United States (2011) \\
\hline France Robots Initiatives (Feuille de Route du Plan Robotique) & France (2013/2014) \\
\hline Robotics Project Horizon 2020 & European Union (2015) \\
\hline New Industrial Revolution Driven by Robots ('Robot Revolution') & Japan (2015) \\
\hline Next-Gen Industrial RobotizationSouth Korea (2015) & South Korea (2015) \\
\hline Robotics Technology Roadmap in 13th Five-Year Plan (2016-2020) & China (2015) \\
\hline Source: compiled by the authors. & \\
\hline
\end{tabular}

${ }^{13}$ Regulation concerning UAVs exists in Canada, Australia, the United States, and in European countries whose airspace is regulated by the European Aviation Safety Agency. The United Nations is proposing to introduce amendments to the 1968 Vienna Convention on Road Traffic in consideration of driverless/autonomous vehicle technology [UN, 2014].; Legislation also exists in several states of the United States concerning driverless cars, including in California (SB 1298), Florida (CS/HB1207), Michigan (SB 0169, 0663), Nevada (AB 511, SB 140), and the District of Columbia (B19-0931). 
robotics-focused associations and groups has certain shortcomings in the way that they are used herein. Nonetheless, it appears that the shortcomings are minor and do not significantly impact the conclusions derived from the data (Figure 2 and footnote 4 ).

The main unit of analysis is the first filing of a given invention. Mappings include registration data on utility models whenever available. Consequently, the date of reference for patent counts is the date of first filing. The only departure from this approach occurs when analysing the share of patent families requesting protection in each patent office (Figure 7). In this case, we used an extended patent family definition - known as the INPADOC patent family - rather than relying on first filings. In addition, only patent families with at least one granted application have been considered for this analysis, and the date of reference is the earliest filing within the same extended family. The main rationale for using the extended patent family definition and imposing at least one granted patent within the family is to mitigate any underestimation. Underestimation could be a problem because of complex subsequent filing structures (such as continuations and divisionals), and small patent families of lower quality (such as those filed in only one country and either rejected or withdrawn before examination).

The origin of the invention is attributed to the first applicant of the first filing; when this information was missing, we applied an imputation strategy. When information about the first applicant's country of residence in the first filing was missing, we adopted the following sequence:

- Extract country information from the applicant's address and name;

- Check information about the companies referred to;

- Rely on the most frequent first applicant or first inventor's country of residence within the same patent family (using the extended patent family definition), or the IP office of the first filing as a proxy for origin.

We categorized applicants into three broad categories:

- State-owned and private companies;

- Government institutions (ministries, state departments, and related entities), public research organizations, and public and private universities;

- Individuals, including those who may or may not be affiliated with companies, research organizations, or other entities.

All unclassified first applicants were grouped into a fourth category called 'data unavailable'.

To assign broad type categories to each first applicant, we performed a series of automated steps for each of the six innovation fields underlying the case studies. We manually cross-checked the results of this automated process, particularly for the top applicants of each type. This prompted us to revise the strategy and adjust the parameters in several iterations.

The starting point was the original information about the first applicant's name from the first filing. When this name was missing, we used the most frequent first applicant's name within the same patent family using the extended definition. We automatically parsed this list of improved first applicants' names in several iterations to: (i) harmonize capital and small letters; (ii) remove symbols and other redundant information (such as stop words and additional geographical references that are useful to get information on applicants' country of residence); and (iii) obtain any valuable information on applicant names to determine whether the applicant is affiliated with a company or research or public sector organization.

Subsequently, we carried out a fuzzy string search using Stata's matchit command to detect alternative spellings and misspellings in applicant names. ${ }^{14}$ Consolidating the corporations also meant we could reclassify some unclassified applicant names as companies. Finally, we imputed the remaining unclassified records into the category of individuals only when they either appeared as inventors in the same patent or were flagged as individuals in the WIPO Statistics Database for patent families containing a PCT application. Analysis of the unclassified records indicates that most of them have missing applicant names in PATSTAT. Most of these missing names refer to original patent documents not in Latin characters and without subsequent patent filings.

The rankings provided for robotics consolidate the patent filings of different first applicants. We carried out a manual examination and consolidation for the most frequent applicants. Corporate or firm applicants sharing a common ultimate owner were consolidated into one applicant. In the case of the top 30 companies, we used the ownership profiles in the BvD Ownership Database. Only subsidiaries that were directly or indirectly majority-owned were taken into account in the consolidation process.

\section{Patenting: their roles, functions, and potential challenges}

Patents are a particularly important IP right for robotics companies because of the significant amount of capital frequently required for research and development prior to the manufacturing of a commercially ready product. Indeed, the large pre-market research and development costs coupled with slow regulatory clearance can create a context in which trailblazing robotics companies may feel that patent protection is necessary to recoup their investment. In absence of such protection, newcomers would be able to enter the market, after the "trail has already been blazed" at a lower cost for research and development and have to overcome fewer regulatory hurdles [Cooper, 2013; Nobile, Keisner, 2013].

For inventions discoverable through reverse engineering or other legal means, patent protection is typically favoured over trade secrets. It is understood that many robotics companies whose competitive

\footnotetext{
${ }^{14}$ This is available from the Statistical Software Components (SSC) archive and from the WIPO website.
} 


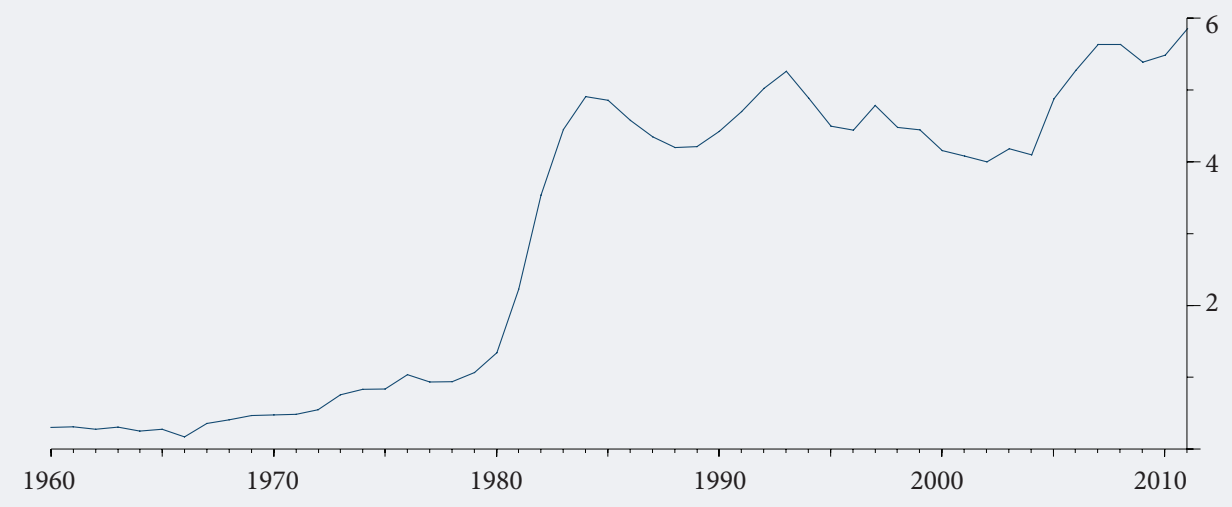

Source: WIPO based on the PATSTAT database.

advantage is perceived to be their sophisticated software designed to enable robotic hardware devices, may use complicated software that cannot be easily reverse-engineered. This is particularly the case with software-based electro-mechanical devices.

Although deterring and excluding competitors is frequently a primary consideration of robotics startups, another common incentive for seeking patent protection concerns the perceived advantages to startups when seeking investment [Keisner, 2012]. This is because, for example, early-stage investors are generally reluctant to sign non-disclosure agreements [Zimmerman, 2014]. This motivation for startups to file patent applications was corroborated by several directors of IP for robotics startups during informal interviews.

As a result, key robotics inventions are frequently patented by their original inventor (who are often researchers). The original inventors then frequently start their own company or transfer their IP to existing manufacturing firms.

In the 1980s, robotics patents increased rapidly as broad-based automation of factories flourished and robotics research was ramped up. Robotics-related first filings approximately quadrupled during this decade (Figure 3). More importantly, these filings outpaced patent filings from other technological fields. The share of total patents from robotics increased from $0.13 \%$ in 1980 to $0.53 \%$ in 1993 (Figure 5).Then, after a relatively flat period of patenting activity during the 1990s and the first half of the 2000s, the shift to more advanced robotics gave another boost to robotics patenting that continues to this day. In a period of increased overall patenting activity, robotics absolute patent filings roughly doubled and the share increased from $0.4 \%$ in 2004 to $0.6 \%$ in 2011 (Figure 5).

The fact that robotics inventive activity is concentrated in a few nations, including the innovating Asian countries, is reinforced by patent data. Figure 3 shows the number of first patent filings worldwide in robotics between 1960 and 2012. It shows the importance of the US, Europe, and later Japan, in the innovation. The recent emergence of South Korea in the early 2000s and then China as important players is noteworthy [UKIPO, 2014]. While the share of China in total robotics patents in 2000 was only $2 \%$, that figure rose to $37 \%$ by 2011 . South Korea's share stood at $17 \%$ in 2011 , while Japan's share fell from $45 \%$ in 2000 to $10 \%$ in $2011 .^{15}$

Figure 6 indicates the origin of first patent filers in two periods, 1980-1990 and 2000-2012. In the more recent period, the countries with the highest number of filings are Japan, China, South Korea, and the US, with each filing more than 10,000 patents and together accounting for about 75 percent of robotics patents. This feat is followed by Germany with roughly 9,000 patents and France with over 1,500. Other countries such as Australia, Brazil, a number of Eastern European countries, the Russian Federation, and South Africa also show new robotics patenting activity, albeit at a lower level.

Indeed, in terms of robotics innovation and company startups, the majority of activity rests in highincome countries, except for China.

Robotics patenting is geographically highly concentrated, with Japan as the leading destination (accounting for close to $39 \%$ of all robotics patents), followed by the US and China (with almost 37\%), and Germany with 29\%. Other major European countries and South Korea are close behind. On the other hand, only $1.4 \%$ of all robotics patents are filed on average in low- and middle-income countries.

Automotive and electronics companies are still the largest filers of patents relating to robotics (Table 3). Yet new actors are emerging from different countries and sectors such as medical technologies. These

\footnotetext{
${ }^{15}$ Note that proportions are calculated considering only first filings with at least one patent granted within the patent family.
} 
firms' robotics patent portfolios are increasing, as firms file patents themselves thanks to their own R\&D or purchase companies with a stock of granted patents.

The large and growing stock of patents owned by universities and PROs is noteworthy too. Table 4 lists the most important patent holders, now largely dominated by Chinese universities. This facilitates the commercialization of new technologies but also poses new challenges for managing these sizeable portfolios.

It is challenging to understand the various factors leading firms to file for patents. No large-scale survey of robotics firms or other solid quantitative work exists that would shed light on this question. Providing a definitive answer on the impacts of robotics patenting on innovation via disclosure, licensing, and IP-based collaboration is also difficult. However, several findings emerge from the views of industry experts, including both lawyers and roboticists. As in other high-tech sectors, robotics firms seek to use patents to exclude third parties, secure freedom to operate, license and cross-license technologies and, to a lesser extent, avoid litigation. For small and specialized robotics firms
Table 3. Top 10 robotics patent filers: 1995 - present

\begin{tabular}{|l|c|c|}
\hline \multicolumn{1}{|c|}{ Company } & Country & $\begin{array}{c}\text { Number of first } \\
\text { patent filings }\end{array}$ \\
\hline Toyota & Japan & 4189 \\
\hline Samsung & South Korea & 3085 \\
\hline Honda & Japan & 2231 \\
\hline Nissan & Japan & 1910 \\
\hline Bosch & Germany & 1710 \\
\hline Denso & Japan & 1646 \\
\hline Hitachi & Japan & 1546 \\
\hline Panasonic (Matsushita) & Japan & 1315 \\
\hline Yaskawa & Japan & 1124 \\
\hline Sony & Japan & 1057 \\
\hline Source: WIPO based on the PATSTAT database. \\
\hline \multicolumn{2}{|l}{} \\
\hline
\end{tabular}

\section{Figure 6. Dynamics of geographical diversity in robotics innovation (number of first patent filings globally)}

a) $1980-1990$

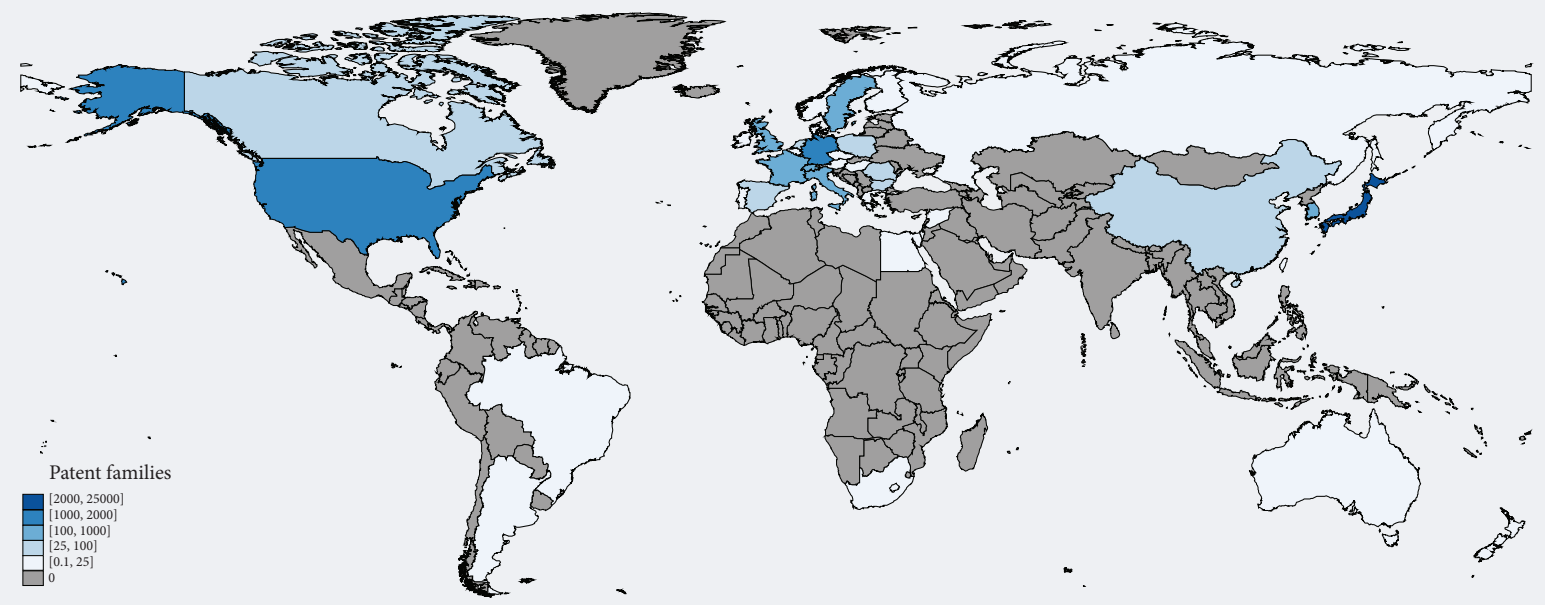

b) 2000-2012

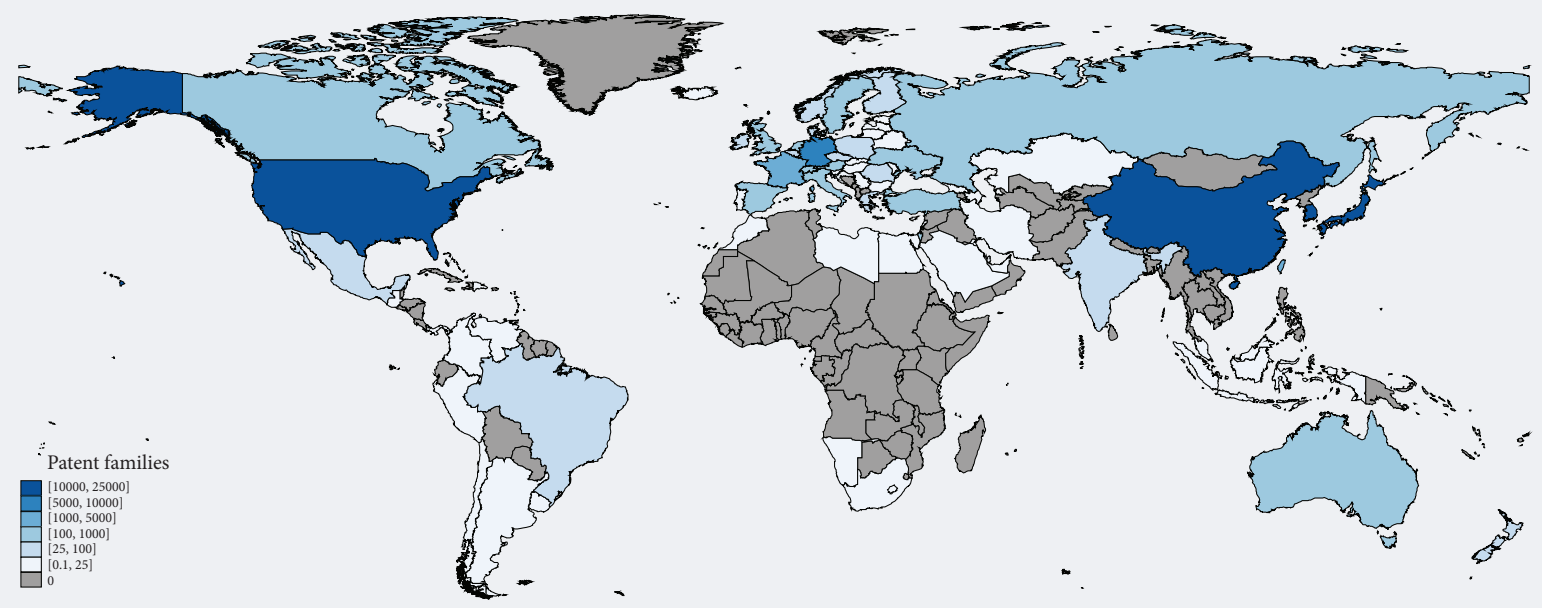

Source: WIPO based on the PATSTAT database. 


\section{Table 4. Top-10 robotics patent holders among universities and PROs, 1995 - present}

\begin{tabular}{|c|c|c|}
\hline Name of organization & $\begin{array}{c}\text { Number of } \\
\text { patents issued }\end{array}$ & Country \\
\hline \multicolumn{3}{|c|}{ Top 10 patenting worldwide } \\
\hline Shanghai Jiao Tong University & 811 & China \\
\hline Chinese Academy of Sciences & 738 & China \\
\hline Zhejiang University & 300 & China \\
\hline Korea Institute of Science and Technology, KIST & 290 & South Korea \\
\hline Electronics and Telecommunications Research Institute, ETRI & 289 & South Korea \\
\hline Tsinghua University & 258 & China \\
\hline Harbin Engineering University & 245 & China \\
\hline National Aerospace Laboratory & 220 & Japan \\
\hline Harbin Institute of Technology & 215 & China \\
\hline Korea Advanced Institute of Science and Technology, KAIST) & 188 & South Korea \\
\hline \multicolumn{3}{|c|}{ Top 10 patenting worldwide (excluding China) } \\
\hline Korea Institute of Science and Technology, KIST & 290 & South Korea \\
\hline Electronics and Telecommunications Research Institute, ETRI & 289 & South Korea \\
\hline National Aerospace Laboratory, JAXA & 220 & Japan \\
\hline KAIST & 188 & South Korea \\
\hline Deutsche Zentrum für Luft- und Raumfahrt & 141 & Germany \\
\hline Fraunhofer-Gesellschaft zur Förderung der angewandten Forschung) & 91 & Germany \\
\hline University of Korea & 85 & South Korea \\
\hline Hanyang University & 84 & South Korea \\
\hline Seoul National University & 77 & South Korea \\
\hline National Institute of Advanced Industrial Science and Technology, AIST & 69 & Japan \\
\hline \multicolumn{3}{|c|}{$\begin{array}{l}\text { Note: Depending on the legislation and policy in place, academic inventors may file patents under their own name or that of their spin-off company in } \\
\text { certain countries [WIPO, 2011]. These patent filings are not captured here. }\end{array}$} \\
\hline \multicolumn{3}{|l|}{ Source: WIPO based on the PATSTAT database. } \\
\hline
\end{tabular}

\section{Figure 7. Main geographical areas of robotics patenting (share of robotics-related patent families} worldwide for which applicants have sought protection in a given country)

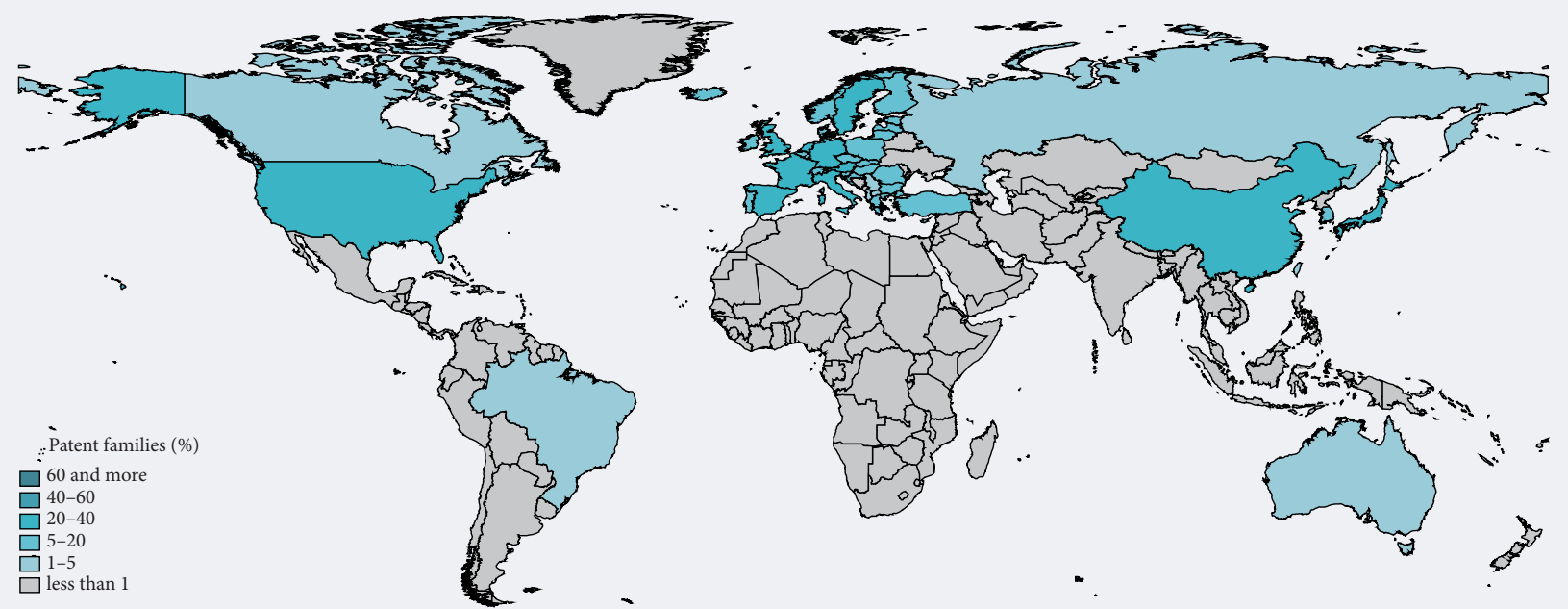

Source: WIPO based on the PATSTAT database. 
in particular, patents are a tool to seek investment or defensively protect their IP assets against other, often larger companies. In terms of the impacts of patenting on innovation, at present the innovation system appears relatively fertile. Collaboration - including between universities and industry - is strong, and there is extensive cross-fertilization of research. Patents seemingly help firms specialize, which is important for the evolution of the robotics innovation system. It is also true that patenting prevents market entry or restricts robotics innovation by limiting access to technology. The available evidence shows little or no litigation occurring in the field of robotics. Indeed, most of the disputes over robotics IP in the past 10 years have involved just one company, iRobot.

Moreover, the importance of particular patents for robotics innovation is hard to verify. Currently, no patents have been flagged as standard-essential, and no known patent pools exist in the area of robotics. Further, there are few formal and disclosed collaborations or exchanges in which IP is central. Only one major licensing deal in the recent history of robotics has received much attention: the joint development and cross-licensing deal between iRobot Corp and InTouch Technologies in July 2011. That said company acquisitions involving the transfer of IP are growing steadily.

Firms use patents to learn about new technology developments, gain insights into competitors' plans for improving or creating products, and to find out whether competitors are attempting to obtain patent protection that should be challenged. Forward patent citations within and outside robotics are often used as an indicator of incremental innovation; that is, of processes in which earlier inventions are built upon. However, especially in the US patent system, forward patent citations are a mere legal obligation, making impact assessment harder. As a result, the overall value of patent disclosure in the area of robotics remains largely unassessed.

Many of the above questions will only be resolved over time. Arguably, IP is not yet fully used in advanced robotics and so its potential impact remains to be realized. Compared with the past, today's robotic innovation system involves more actors, new technology fields, and significantly more patent filings. We can start to see more intensive, offensive, and defensive IP strategies that are present in other hightechnology fields.

A vital question is whether the increased stakes and commercial opportunities across various sectors will tilt the balance toward costly litigation, as in the case of other high-tech and complex technologies. For the moment, the number of IP disputes involving robotics companies is too small to extract any meaningful insight about the effectiveness of the IP system. One noticeable trend is that the majority of IP disputes over the past ten years involved a single well-known United States based robotics company (iRobot Corp). These lawsuits include one in 2005 against Koolatron \& Urus Indus; one in 2007 against Robotic FX; several in 2013 in Germany against Elektrogeräte Solac Vertrieb GmbH, Electrodomésticos Solac S.A., Celaya, Emparanza y Galdos Internacional S.A., Pardus GmbH, and Shenshen Silver Star. ${ }^{16}$ To date, there has only been one recent IP dispute in which the lawsuit went to a final judgment and appeal. ${ }^{17}$ This makes it difficult, if not impossible, to assess whether the judicial system adequately resolves IP disputes involving robotics related technologies.

There have been few cases in which non-practicing entities have targeted robotics companies with a lawsuit. ${ }^{18}$ In particular, press reports mention the dangers of patent trolling in the field of surgical robots and medical robotics.

Two elements could increase the likelihood of disputes. First, experts consulted in this study have raised concerns that overly broad claims are being made in the case of robotics patents, especially with respect to older patents. While patent infringement disputes between robotics companies appear to be resolved effectively by current judicial systems, ${ }^{19}$ certain patent infringement disputes have led some professionals within the robotics industry to question the breadth of patent claims contained in older patents [Tobe, 2012].

Second, in certain countries the patentability and novelty of computer-related inventions generally are a matter of debate. This is particularly true in the US, where the recent Supreme Court decision in Alice Corp. vs. CLS Bank seems to have reinforced a restrictive approach towards patent eligibility of software [Thayer, Bhattacharyya, 2014a, 2014b]. Given the large and growing software-related component of robotics innovation, concerns about software patentability may pose a challenge in relation to current and future robotics-related patents.

\section{Robotics platforms: the co-existence of IP and open source}

As described earlier, robotics platforms in universities and businesses have become central to robotics innovation. Such platforms, such as the Robot Operation System (ROS), are increasingly based on open source software. Open source robotics platforms invite third parties to use and/or improve existing content without the formal negotiation or registration of IP rights. Instead, software or designs are

\footnotetext{
${ }^{16}$ For more detail on these lawsuits and their conclusions, see [Keisner et al., 2015].

${ }^{17}$ This was the lawsuit between the firms InTouch Health and VGo Communications, which both independently developed telepresence robots. For more detail, see [Keisner et al., 2015; Nobile, 2013].

${ }^{18}$ Some examples include the lawsuits between Roy-G-Biv. Corp. v. Fanuc Ltd. (in 2007), and Roy-G-Biv Corp. v. ABB, Ltd. Honeywell Int'l, Inc., and Siemens Corp. (all in 2011). For more detail, see [Keisner et al., 2015].

${ }^{19}$ It should be noted that, for the purpose of this study, the effective resolution of an IP dispute does not take into consideration the resources expended by companies in asserting or defending a claim, which varies greatly between countries based on differences in judicial systems. This includes the large difference in resources expended in a lawsuit based on discovery rules and whether there are fee-shifting rules.
} 
distributed under Creative Commons or GNU General Public License, a free software license, which allows for rapid prototyping and flexible experimentation.

The core idea is simple. Actors distinguish between two stages of innovation. In the early stages, there is the collaborative development of robotics software, platforms, and innovation. Such innovation may be substantial, but it is essentially pre-competitive because the fields of use are relatively basic and do not serve to differentiate products. Actors therefore apply cooperative open source approaches to obtain common robotics platforms, as this allows them to share the substantial up-front investment needed, avoid duplication of effort, and perfect existing approaches.

In the later stages, innovative firms invest in their own R\&D efforts and strive to protect their inventions far more vigorously, especially those elements of robotics innovation that differentiate end-products.

This parallel application of cooperative and competitive approaches results in a co-existence of competitive and open source-inspired approaches to handling IP.

Various non-profit organizations and projects support the development, distribution, and adoption of open-source software for use in robotics research, education, and product development. The iCub, for instance, is an open-source cognitive humanoid robotics platform funded by the EU, which has been adopted by a significant number of laboratories. Poppy is an open-source platform developed by INRIA Bordeaux for the creation, use, and sharing of interactive 3D-printed robots. Other examples include the Dronecode project and the NASA International Space Apps Challenge.

This trend could entail an increasing shift toward engaging end-users or amateur scientists to interact with and improve existing robotics applications. In fact, many user-oriented, low-cost platforms built for home or classroom use, like TurtleBot and LEGO Mindstorms, are built on open source platforms.

This open-platform approach is not limited to software; it can also encompass blueprints such as technical drawings and schematics, including designs. The Robotic Open Platform (ROP), for instance, aims to make hardware designs of robots available to the robotic community under an Open Hardware license, whereby advances can be shared within the community.

In general, it will be interesting to see how well the robotics innovation system preserves its current fluid combination of proprietary approaches for those aspects of IP where the commercial stakes are higher. The same can be said for non-proprietary approaches to promote more general aspects of relevant science through contests and collaboration among young roboticists and amateurs interested in opensource applications. In light of the high degree of collaboration in the robotics industry, as well as many countries' interest in fostering robotics innovation, it is timely for countries to re-examine their laws on joint IP ownership. Many national laws on joint IP ownership produce unexpected and unfair results in practice, unless the persons or entities involved contract around such laws.

\section{Protecting robotic breakthroughs via technological complexity and secrecy}

Potentially more important than patents, the technological complexity and secrecy of robotics systems are often used as a key tool to appropriate innovation. This is true for standard mechanical, hardware-related components. There are multiple reasons why a robotics company may prefer to keep certain technologies or information as trade secrets rather than seeking patent protection. The first two reasons, which are not necessarily unique to robotics, are related either to the difficulty in obtaining patent protection or to the issue that IP could not be reverse engineered by even the most sophisticated competitors. This is frequently the case with robotics companies who believe that their manufacturing process could not be identified without a competitor actually observing the manufacturing process. The same is frequently true for testing methods of a robot's performance. However, some robotics companies have survived with relatively few competitors, and believe that their work, although comprised of software and hardware, is so advanced that only a select few could reverse engineer their products. Robotics companies that make a limited number of highly expensive robots are typically not afraid that competitors will gain physical possession of such robots to reverse engineer them, as that proposition is often impracticable [Keisner, 2013 b].

Additionally, many small and mid-size robotics companies prefer trade secrets because they want to avoid the onerous costs and fees that come with filing patent applications.

There are also historical reasons why robotics companies choose to retain information as trade secrets. In the 1980s, robotics made several significant advances and firms filed many patents (Figures 3 and 5). However, only a few of these inventions were commercialized quickly. In other words, firms spent large amounts of money to obtain patents that expired before their products were commercialized. Thus, patents can be costly without necessarily bringing any reward, especially for innovations that may be decades away from use in a market-ready product.

Trade secret protection is also important when employee mobility is high. Robotics companies have sought to protect their trade secrets when an employee joins a competitor. Many robotics companies bolster the protection of their trade secrets with restrictive covenants as permitted by the relevant jurisdiction. $^{20}$

Finally, the recent questions around the patentability of software in the US and elsewhere could increase the incentive to protect related inventions via secrecy.

\footnotetext{
${ }^{20}$ For example, MAKO Surgical Corp.'s lawsuit against Blue Belt Technologies, and ISR Group's lawsuit against Manhattan Partners. For more detail, see [Keisner, 2013a, b; Keisner et al., 2015; Cole, 2014].
} 


\section{The role of being first-to-market, reputation, and strong brands}

Being first to market, a strong after-sales service, reputation, and brand name, have all been critical in past robotics innovation, and remain so today, especially since the industry has moved away from serving factories and into applications with direct consumer contact.

In the case of industrial automation, automotive companies prefer to only deal with a few trusted operators who are able to produce many reliable robots and service them dependably. Initially, Unimation dominated the supply of industrial robots; later, large firms such as Fanuc held sway. Experience and a solid reputation and brand continue to be critical in the health sector, educational institutions, and the military. Examples of such trusted brand names in the area of medical robot makers are DaVinci surgical robot, CorPath vascular surgery robots, and the Accuray CyberKnife Robotic Radiosurgery System. In the military and related fields, brands also matter as evidenced by the use of trademarks such as Boston Dynamics' 'BigDog. Strong brands are particularly important when robots are sold directly to end-users; for example, the 'Roomba vacuum cleaner' relies strongly on its trademark value.

Most companies trademark their company names and robot names. This means that a growing number of trademarks include the term 'robot'.

\section{Industrial design rights and trade dress}

Next to patents, industrial designs that protect the ornamental features of a robot as registered IP forms also play an important role in helping firms appropriate the returns to their investments in R\&D.

Another form of IP is trade dress, a source-designating type of IP that refers generally to the total image of a product [Reese, 1994; USPTO, 2014]. Within the robotics industry, trade dress is a right generally used to describe the total image of a robot or robotics product. ${ }^{21}$ Some nations do not distinguish between trade dress rights and trademark rights as both are considered source-identifying forms of IP. Other countries provide protection for trademark rights under a sufficiently broad definition such that it could be extended to other source-identifying forms of IP, including registered trade dress rights. ${ }^{22}$

Within the robotics industry, there are only a few examples of lawsuits asserting trade dress infringement claims based on the 'look and feel' of a robot. However, there are no known cases in which such a trade dress infringement claim has been entertained. ${ }^{23}$

\section{Copyright and robotics}

The issue of copyright protection is relevant to robotics in several respects. Copyright protection is especially an issue in the area of software codes that have been 'reduced to writing' and are believed to be unique and original. In practice, robotics companies typically use copyright enforcement to prevent others from copying or simply accessing their computer code. Another example where copyright protection could be used for robotics but is not a common practice in the industry is for a unique aesthetic design, such as a design pattern on a robot.

It is generally accepted within most countries that circumventing an electronic barrier in order to gain access to copyrightable computer code is a violation of the 1996 WIPO Copyright Treaty (Article 11). This is particularly important for the robotics industry because most robotics companies employ electronic barriers to restrict access to their robot's computer code. In the United States, the case law over the past several years also shows a trend suggesting that the US, which is a signatory to the WIPO Copyright Treaty, would need to conform to the laws of most other nations and Article 11 of the WIPO Copyright Treaty. Circumventing an electronic barrier to access copyrightable code - even if there is no act of copying giving rise to an independent claim for copyright infringement - would still constitute a violation of the United States' Digital Millennium Copyright Act (DMCA), which is the United States' implementation of the WIPO Copyright Treaty [US Senate, 1998; Keisner, 2012]. The European Union has similarly taken measures to harmonize its laws with the WIPO Copyright Treaty by prohibiting the circumvention of electronic barriers to access protected copyrightable works: for example, the implementation of Article 6 of the European Directive 2001/29/EC [European Parliament, 2001].

Despite the fact that some national laws may provide for reverse engineering exceptions, copyright related anti-circumvention laws have also been invoked when an amateur scientist decrypts and changes software code. Although never to date the subject of a court decision, there have been cases where companies have made claims regarding violation of the US Digital Millennium Copyright Act (DMCA) due to unauthorized access to the company's robot's software code. For instance, when a hacker decrypted the software code for Sony's robotic-dog, Aibo, and circulated the new software to other consumers such that they could 'teach' the robotic-dog to speak and dance, Sony asserted that such acts were a violation of the DMCA and demanded the removal of the software [Mulligan, Perzanowski, 2007].

\footnotetext{
${ }^{21}$ Similar to trade dress rights, industrial design rights protect the visual design of an object. As a result of The Hague Agreement Concerning the International Deposit of Industrial Designs, there is now a procedure for international registration of an industrial design, effective in several countries, via a single application [WIPO, 2014].

${ }^{22}$ For example, see India's Trade Marks Act of 1999. In addition, [Tiwari, 2005, p. 480] points out that Indian courts have shown the propensity to address the issues of trade dress protection within the broad parameters of the law on substitution.

${ }^{23}$ For example, the lawsuits between iRobot Corporation and Urus Industrial Corporation (2005) and between Innovation First, Inc. and Urban Trend, LLC (2010). In both cases, the lawsuits were settled and consent judgments filed. For more detail, see [Keisner et al., 2015].
} 


\section{Robot-inventors as the subject of copyright}

In the future, robots - when carrying out set tasks - are likely to produce new solutions to problems, and in so doing potentially create physical or intangible products or outputs. These outputs could (at least in theory) be perceived as IP - new inventions, creative works, or trademarks. This element of robotics innovation could raise interesting questions as to the set-up and boundaries of the current IP system. Are objects, software code, or other assets created autonomously by a robot copyrightable or patentable? If so, how? Further, who would own these IP rights - the producer, the user, or the robot itself? [Leroux, 2012]. Some countries such as Japan and South Korea are seriously considering extending rights to machines.

Some case law is relevant too. For instance, the US Copyright Office recently determined that a photographer did not own the copyright to a photograph taken by a monkey who temporarily 'borrowed' his camera [McAfee, 2014; US Copyright Office Practices, 2014] Given that ruling, some practitioners question whether photographs taken by robots would be protected by copyright - at least in the US [Fischer, 2014; McAfee, 2014].

In the UK, on the other hand, there is dedicated legislation suggesting that copyright protection can be avoided for robot-generated works. Although it is debated how such legislation should be applied, it is nonetheless an area of IP law applicable to robotics in which it appears that contradictory rules are emerging between countries with significant roles in the robotics industry [RoboLaw, 2014, p. 19] . In New Zealand, the law suggests that original works created by a human are still eligible for copyright protection under its 1994 Copyright Act, even if the work is created with the help of software, robots, or artificial intelligent systems [Grierson et al., 2011]. Ownership of such works, however, would belong not to the robot or intelligent system, but instead to the person(s) who created or utilized the robot or intelligent system that ultimately created the work. In comparison, however, IP practitioners in Australia have noted, in light of some of the same case law referenced by New Zealand practitioners, that the laws providing for copyright protection of computer-generated works involve numerous aspects. Moreover, these practical aspects make it difficult to assert protection over a work generated by a computer, robot, or intelligent system [Clark, Kovacic, 2011].

A full legal assessment of the issues relating to autonomous robot creation is beyond the scope of this paper. Nevertheless, the question of who owns the IP rights over creations produced by robots will surely be a matter of future discussions.

\section{Conclusion}

Few studies have analysed the developments of robotics, the underlying innovation eco-system, and the role of IP. Here we aim to fill this gap by providing an up-to-date assessment of the robotics innovation system. We analysed original patent landscape data to shed light on robotics filing strategies and to identify top filers. We also went beyond the use of patents to analyse the role of trade secrets, industrial design, brands, and copyright. To conclude, we demonstrated how developments in the robotics industry could lead to new questions, such as who owns the IP of works or inventions created by robots themselves.

\section{Acknowledgements}

This article is based on a study commissioned by the World Intellectual Property Organization to prepare the report entitled 'World Intellectual Property Report 2015: Breakthrough Innovation and Economic Growth' [WIPO, 2015].

The views expressed in this article are those of the authors and do not necessarily reflect the views of the World Intellectual Property Organization or its member states.

Data for the article were made available by the International Federation for Robotics, and by Frank Tobe (The Robot Report). For their valuable comments and advice, the authors would like to thank Prof. Roland Y. Siegwart (Swiss Federal Institute of Technology, ETH Zürich), Mirko Boehm, and participants of a WIPO Workshop (on February 5-6, 2015 in Geneva) on the above-mentioned study, in particular Roger Burt, Remy Glaisner, Deven Desai, Thomas Hören, and David Mowery.

Richard Corken, Christopher Harrison, and Marian Lilington of the UK IP Office provided valuable advice on the characteristics of patent landscapes. Carsten Fink, Chief Economist at WIPO, and Francesca Guadagno, affiliated with WIPO, provided critical inputs throughout the project.

\section{References}

Anders G. (2014) Amazon's drone team is hiring: Look at these nifty job ads. Forbes, 19.05.2014.

Brynjolfsson E., McAfee A. (2014) The Second Machine Age: Work Progress, and Prosperity in a Time of Brilliant Technologies, New York: W. Norton and Company.

Cameli I., Hamano Y., Jazairy A., Spasic O. (2011) Harnessing Public Research for Innovation - The Role of Intellectual Property (Chapter 4). The Changing Face of Innovation, Geneva: WIPO, pp. 140-183. Available at: http://www.wipo.int/export/sites/www/econ_stat/en/economics/wipr/pdf/wipr_2011_chapter4.pdf, accessed 03.04.2016 
Cellan-Jones R. (2014) Oxford's robots and the funding of innovation. BBC.com, 03.11.2014.

Chen K. (2013) Advantech buys majority stake in LNC. Taipei Times, 31.08.2013.

Christensen H., Goldberg L. Kumar V., Messina E. (2013) A Roadmap for U.S. Robotics - From Internet to Robotics (discussion paper presented at the workshop "Manufacturing and automation robotics", Washington D.C., 02.12.2012). Available at: https://robotics-vo.us/sites/default/files/2013\%20Robotics\%20Roadmap-rs.pdf, accessed 14.12.2015.

Clark T., Kovacic I. (2011) Copyright in works generated by computer programs. Lexology.com, 31.08.2011.

Cole E. (2014) MAKO Surgical Sues Blue Belt Technologies. Robotics Business Review, 10.06.2014.

Cooper D.M. (2013) A Licensing Approach to Regulation of Open Robotics (paper presented at the "We Robot: Getting Down to Business" Conference, Stanford Law School, 08-09.04.2013).

Dockterman E. (2014) Facebook Eyes Using Drones to Deliver Internet. Time Magazine, 27.03.2014.

Economist (2014) Free the Drones. The Economist, 06.12.2014.

euRobotics (2014) Strategic research agenda for robotics in Europe 2014-2020. Available at: http://www.eu-robotics. net/cms/upload/PPP/SRA2020_SPARC.pdf, accessed 10.08.2015.

European Parliament (2001) Directive 2001/29/EC of the European Parliament and of the Council of 22 May 2001. Official Journal of the European Communities, L 167/10, 22.06.2001.

Falconer J. (2014) Patent Suggests Sony Still Sees Future for Household Robots. IEEE Spectrum, 14.04.2014.

Fischer M.A. (2014) Are Copyrighted Works Only by and for Humans? The Copyright Planet of the Apes and Robots. Duane Morris New Media and Entertainment Law Blog, August 18.08.2014.

Frey C.B., Osborne M.A. (2013) The future of employment: How susceptible are jobs to computerisation? (Working Paper Oxford Martin Programme on the Impacts of Future Technology), Oxford: Oxford University.

Gamell M. (2014) Crowdsourcing for Designing the New Amazon Robots. ARISPlex, 20.11.2014.

Garside J. (2014) Facebook Buys UK Maker of Solar-Powered Drones to Expand Internet. The Guardian, 28.03.2014.

Green T. (2012) Robots, Re-Shoring and America's Manufacturing Renaissance. Robotics Business Review, 10.06.2012.

Green T. (2013) Rising Power and Influence of Robotics Clusters. Robotics Business Review, 22.02.2013.

Grierson S., Gray E., Scott R. (2011) If Shakespeare were a robot, would "he" be an "author"? Lexology.com, 28.02.2011. Halzack S. (2014) Elance-oDesk flings open the doors to a massive digital workforce. The Washington Post, 13.06.2014.

IFR (2012) History of Industrial Robots: From the first installation until today. Frankfurt am Main: International Federation of Robotics.

IFR (2014a) World Robotics 2014: Industrial Robots, Frankfurt am Main: International Federation of Robotics.

IFR (2014b) World Robotics 2014: Service Robots, Frankfurt am Main: International Federation of Robotics.

IFR (2015) Service Robots. Available at: http://www.ifr.org/service-robots/, accessed 03.08.2015.

InTouch Health (2011) iRobot and InTouch Health Announce Agreement to Explore Potential Opportunities in Healthcare Market (Press Release, 20.07.2011). Available at: http://www.intouchhealth.com/media/pressrelease/07-20-2011/, accessed 17.06.2014.

Keisner C., Raffo J., Wunsch-Vincent S. (2015) Breakthrough Technologies - Robotics, Innovation and Intellectual Property (WIPO Economics and Statistics Series, November 2015), Geneva: World Intellectual Property Organization. Available at: http://www.wipo.int/edocs/pubdocs/en/wipo_pub_econstat_wp_30.pdf, accessed 27.03.2016

Keisner C.A. (2012) Making Your Robotics Company A More Attractive Investment. Robotics Business Review, 21.10.2012.

Keisner C.A. (2013a) Robotics and Intellectual Property (paper presented at the Incremental Advantage Webinar by Davis and Gilbert LLP, March 2013).

Keisner C.A. (2013b) Keeping Things Confidential: Robotics Trade Secrets 1.0. Robotics Business Review, 21.10.2013.

Kumaresan N., Miyazaki K. (1999) An integrated network approach to systems of innovation - The case of robotics in Japan. Research Policy, vol. 28, no 6, pp. 563-585.

Leroux C. (2012) EU Robotics Coordination Action: A green paper on legal issues in robotics (Paper presented at the International Workshop on Autonomics and Legal Implications, Berlin, 02.11.2015).

Letzing J. (2012) Amazon Adds That Robotic Touch. The Wall Street Journal, 20.03.2012.

Manyika J., Chui M., Bughin J., Dobbs R., Bisson P., Marrs A. (2013) Disruptive Technologies: Advances that will Transform Life, Business, and the Global Economy. New York: McKinsey Global Institute.

McAfee D. (2014) Copyright Office Says It Will Not Register 'Monkey Selfie'. Law 360, 22.08.2014.

McNeal G.S. (2014) Google Wants Internet Broadcasting Drones, Plans To Run Tests In New Mexico. Forbes, 19.09.2014.

Metra Martech (2011) Positive Impact of Industrial Robots on Employment, London: Metra Martech Limited.

Miller B., Atkinson R.D. (2013) Are Robots Taking Our Jobs, or Making Them?, Washington, D.C.: The Information Technology and Innovation Foundation.

Mireles M.S. (2006) States as Innovation System Laboratories: California, Patents, and Stem Cell Technology. Cardozo Law Review, no 1133(374), pp. 1147-1149.

Mulligan D.K., Perzanowski A.K. (2007) The Magnificence of the Disaster: Reconstructing the Sony BMG Rootkit Incident. Berkeley Technology Law Journal, vol. 22, no 3, pp. 1157-1232.

Nobile C. (2013) The IP Battle Continues For Robotics Companies. Robotics Business Review, 07.01.2013.

Nobile C., Keisner C.A. (2013) The IP Battle Continues for Robotics Companies: A Patent Attorney's Reprise of the VGo/InTouch Health Verdict and its Implications. Robotics Business Review, 07.01.2013.

Nof S.Y. (1999) Handbook of Industrial Robotics, West Sussex: Wiley.

Pilkington E. (2014) What's keeping America's private drone industry grounded? The Guardian, 30.09.2014. 
RBR Staff (2012) China 2013: Factory Automation Driving Robot Growth. Robotics Business Review, 28.12.2012. RBR Staff (2013a) iRobot Obtains Injunction against Shenzhen Silver Star. Robotics Business Review, 06.09.2013.

RBR Staff (2013b) Mining Giant Anglo-American Inks Deal with Carnegie Mellon. Robotics Business Review, 09.01.2013.

Reese J.W. (1994) Defining the Elements of Trade Dress Infringement under Section 43(a) of the Lanham Act. Texas Intellectual Property Law Journal, Winter, pp. 103-132.

Robotics Trends Staff (2007) Autonomous Solutions Awarded Contract to Develop an Immersive UI. Robotic Trends, 05.07.2007.

Romano J. (2014) Amazon Picking Challenge. RoboHub, 04.11.2014.

Rosheim M.E. (1994) Robot Evolution: The Development of Anthrobotics, New York: John Wiley \& Sons, Inc.

Scheinman V. (2015) Robotics History Narratives (Interview, 10.08.2015). Available at: http://roboticshistory.indiana. edu/content/vic-scheinman, accessed 15.11.2015.

Smith R.C., Cheeseman P. (1986) On the Representation and Estimation of Spatial Uncertainty. The International Journal of Robotics Research, vol. 5, no 4, pp. 56-68.

Springer P.J. (2013) Military Robots and Drones: A Reference Handbook, Santa Barbara: ABC-CLIO.

SSSA (2014) Guidelines Regulating Robotics, Washington, D.C.: Soil Science Society of America.

Technopolis, University of Manchester (2011) Case Study on the demand-side elements of the Danish innovation policy mix. Available at: https://www.mkm.ee/sites/default/files/case_study_market_development_fund_denmark.pdf, accessed 23.04.2015.

Thayer L., Bhattacharyya A. (2014a) Will Supreme Court Rein in Software Patents? Robotics Business Review, 04.03.2014.

Thayer L., Bhattacharyya A. (2014b) Patent Eligibility of Software in the Wake of the Alice Corp. v. CLS Bank Decision. Robotics Business Review, 14.08.2014.

Tiwari A. (2005) Passing off and the Law on 'Trade Dress' Protection: Reflections on Colgate v. Anchor. Journal of Intellectual Property Rights, vol. 10, pp. 480-490.

Tobe F. (2012) The patent grip loosens. Everything-Robotics, 06.12.2012.

Tobe F. (2015) The Robot Report's Global Map. Available at: http://www.therobotreport.com/map, accessed 10.08.2015.

U.S. Copyright Office (2014) Compendium of U.S. Copyright Office Practices ( ${ }^{\text {rd }}$ ed., public draft - not final, 19.08.2014), Washington, D.C.: U.S. Copyright Office.

U.S. Senate (1998) Report on the Digital Millennium Copyright Act of 1998, Washington, D.C.: U.S. Senate. Available at: https://www.gpo.gov/fdsys/pkg/CRPT-105srpt190/pdf/CRPT-105srpt190.pdf, accessed 21.11.2015.

UKIPO (2014) Eight Great Technologies - Robotics and Autonomous Systems: A Patent Overview, London: UK Intellectual Property Office.

UN (2014) Report of the Sixty-Eighth Session of the Working Party on Road Traffic Safety, 17.04.2014 (ECE/Trans/ WP.1/145), Vienna: United Nations.

USPTO (2014) Trademark Manual of Examining Procedure, Washington, D.C.: U.S. Patent and Trademark Office.

Walker J. (2013) Tess Stynes, Stryker to Acquire MAKO Surgical for About \$1.65 Billion. The Wall Street Journal, 25.09.2013.

Wintergreen Research Inc. (2015) Surgical Robots Market Shares, Strategies, and Forecasts, Worldwide, 2015 to 2021, Dublin: Research and Markets.

WIPO (2014) Guide to the International Registration of Industrial Designs under the Hague Agreement (WIPO Publication no 857(E), 2nd ed.), Geneva: WIPO.

WIPO (2015) Breakthrough Innovation and Economic Growth, Geneva: WIPO.

Zimmerman E. (2014) Why More Start-Ups Are Sharing Ideas Without Legal Protection. The New York Times, 02.07.2014 